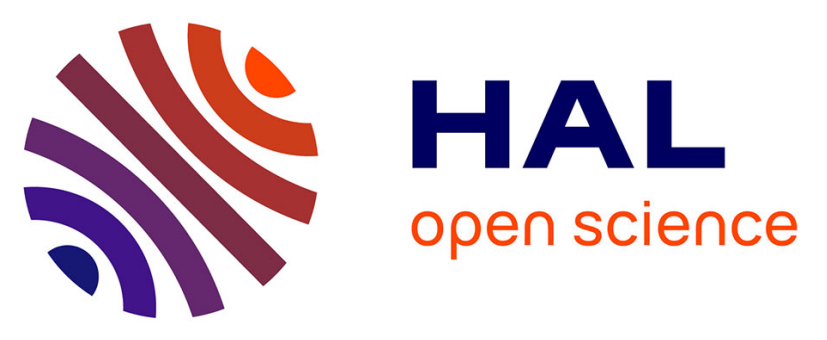

\title{
Optimisation of the dynamical behaviour of the Anisotropic United Atom Model of branched alkanes. Application to the molecular simulation of fuel gasoline
}

\author{
Carlos Nieto-Draghi, Anthony Bocahut, Benoît Creton, Pascal Have, Aziz
}

Ghoufi, Aurélie Wender, Boutin Anne, Bernard Rousseau, Laurent Nomand

\section{To cite this version:}

Carlos Nieto-Draghi, Anthony Bocahut, Benoît Creton, Pascal Have, Aziz Ghoufi, et al.. Optimisation of the dynamical behaviour of the Anisotropic United Atom Model of branched alkanes. Application to the molecular simulation of fuel gasoline. Molecular Simulation, 2008, 34 (02), pp.211-230. 10.1080/08927020801993370 . hal-00515029

\section{HAL Id: hal-00515029 \\ https://hal.science/hal-00515029}

Submitted on 4 Sep 2010

HAL is a multi-disciplinary open access archive for the deposit and dissemination of scientific research documents, whether they are published or not. The documents may come from teaching and research institutions in France or abroad, or from public or private research centers.
L'archive ouverte pluridisciplinaire HAL, est destinée au dépôt et à la diffusion de documents scientifiques de niveau recherche, publiés ou non, émanant des établissements d'enseignement et de recherche français ou étrangers, des laboratoires publics ou privés. 


\section{Molecular Simulation \\ Journal of \\ Experimental Nanoscience

\section{Optimisation of the dynamical behaviour of the Anisotropic United Atom Model of branched alkanes. Application to the molecular simulation of fuel gasoline}

\begin{tabular}{|c|c|}
\hline Journal: & Molecular Simulation/Journal of Experimental Nanoscience \\
\hline Manuscript ID: & GMOS-2007-0180.R1 \\
\hline Journal: & Molecular Simulation \\
\hline $\begin{array}{r}\text { Date Submitted by the } \\
\text { Author: }\end{array}$ & $13-F e b-2008$ \\
\hline Complete List of Authors: & $\begin{array}{l}\text { Nieto-Draghi, Carlos; IFP, Thermodynamic and Molecular } \\
\text { Simulation Department } \\
\text { Bocahut, Anthony; IFP, Thermodynamic and Molecular Simulation } \\
\text { Department } \\
\text { Creton, Benoît; IFP, Thermodynamic and Molecular Simulation } \\
\text { Department } \\
\text { Have, Pascal; IFP, Thermodynamic and Molecular Simulation } \\
\text { Department } \\
\text { Ghoufi, Aziz; IFP, Thermodynamic and Molecular Simulation } \\
\text { Department } \\
\text { Wender, Aurélie; Univ. Paris-Sud, Laboratoire de Chimie-Physique; } \\
\text { IFP, Thermodynamic and Molecular Simulation Department } \\
\text { Anne, Boutin; Univ. Paris-Sud, Laboratoire de Chimie-Physique } \\
\text { Rousseau, Bernard; Univ. Paris-Sud, Laboratoire de Chimie- } \\
\text { Physique } \\
\text { Nomand, Laurent; IFP, Thermodynamic and Molecular Simulation } \\
\text { Department }\end{array}$ \\
\hline Keywords: & $\begin{array}{l}\text { Anisotropic United Atom, branched alkanes, transport properties, } \\
\text { olefins, fuel gasoline }\end{array}$ \\
\hline
\end{tabular}

\section{SCHOLARONE Manuscripts}




\section{Page 1 of 57}

1

2

3

4

5

6

7

8

9

10

11

12

13

14

15

16

17

18

19

20

21

22

23

24

25

26

27

28

29

30

31

32

33

34

35

36

37

38

39

40

41

42

43

44

45

46

47

48

49

50

51

52

53

54

55

56

57

58

59
RESEARCH ARTICLE

Optimisation of the dynamical behaviour of the Anisotropic United Atom Model of branched alkanes. Application to the molecular simulation of fuel gasoline. 


\section{RESEARCH ARTICLE}

\section{Optimisation of the dynamical behaviour of the Anisotropic United Atom Model of branched alkanes. Application to the molecular simulation of fuel gasoline.}

Carlos Nieto-Draghi ${ }^{\mathrm{a},{ }^{*}}$, Anthony Bocahut ${ }^{\mathrm{a}}$, Benoît Creton ${ }^{\mathrm{a}}$, Pascal Have ${ }^{\mathrm{a}}$, Aziz Ghoufi ${ }^{\mathrm{a}}$, Aurélie Wender ${ }^{\mathrm{a}, \mathrm{b}}$, Anne Boutin $^{\mathrm{b}}$, Bernard Rousseau ${ }^{\mathrm{b}}$, Laurent Normand ${ }^{\mathrm{a}}$

${ }^{\mathrm{a}}$ IFP, 1-4 Avenue de Bois-Préau, 92852 Rueil-Malmaison, Cedex, France, ${ }^{\mathrm{b}}$ Laboratoire de Chimie-Physique, Bâtiment 349,Univ. Paris-Sud, 91405 Orsay Cedex, France

Abstract: In the present work we have optimised the dynamical behaviour of the anisotropic united atom (AUA) intermolecular potential for branched alkanes developed by Bourasseau et al. [Bourasseau, E.; Ungerer, P.; Boutin, A.; Fuchs, A. H. 2002. Mol. Sim., 28, 317], by a modification of the energetic barrier of the torsion potential. The new potential $(\mathrm{AUA}(4 \mathrm{~m}))$ preserves all the intermolecular parameters and only explores an increment in the trans-gauche and gauche+-gauche- transition barrier of the torsion potential. This modification better reproduces transport properties like the shear viscosity, keeping the accuracy achieved in the original work for equilibrium properties. An extensive investigation of the shear viscosity of 12 different types of branched alkanes in a wide range of pressures and temperatures, shows that the AUA $(4 \mathrm{~m})$ improves the accuracy of the original AUA4, reducing the absolute average deviation from $24 \%$ to $15 \%$. In addition, molecular simulation results of the shear viscosity of olefins reveal that the original AUA potential is accurate enough to reproduce the experimental data with less than $12 \%$ of deviation. Finally, we present a consistent lumping methodology to perform molecular simulations on complex multi-component systems such as fuel gasoline by representing the real system by a simplified mixture with only tenths of species.

Keywords: Anisotropic United Atom; transport properties; shear viscosity; branched alkanes; olefins; fuel gasoline; lumping methodology.

* Corresponding author. Email: carlos.nieto@ifp.fr 


\section{Introduction}

The automobile industry recently faces the challenge of developing a new generation of motor engines for more efficient and low consumption vehicles. In addition, new regulations demand the reduction of pollutants and green house gases with different milestones on maximum emissions, i.e. $<0.5$ $\mathrm{g} / \mathrm{km}$ for $\mathrm{CO},<0.3 \mathrm{~g} / \mathrm{km}$ for $\mathrm{HC}+\mathrm{NOx}$, and $<0.18 \mathrm{~g} / \mathrm{km}$ for NOx (2009 regulation for gasoline Euro 5 and Euro 6) [1]. These restrictions are also accompanied with initiatives on the development of flexi-fuel motor engines working with different types of blends of standard gasoline with bio-ethanol, or diesel-bio diesel, in order to reduce $\mathrm{CO}_{2}$ and green house emissions. This fact requires the knowledge of thermo physical properties, such as liquid vapour equilibrium and transport properties, of complex mixtures at different thermodynamic conditions. A systematic campaign of experimental data acquisition on fuel blends is expensive. In certain conditions, such as in high pressure fuel diesel injection (pressures over 3000 bar) the extreme pressure makes experiments dangerous. Correlative equations are adapted at ambient conditions but they can not be used out of their range of application ([2], [3]). Molecular simulation can be used as a good alternative to obtain these physical properties, however, the description of real complex mixtures such as those present in fuels represent a great challenge.

The key point of the validity of the results obtained by means of molecular simulation is the accuracy of the intermolecular potentials employed to describe the different chemical species and the physical properties to be computed. There are several types of intermolecular potentials available in the literature according to the degree of details to describe hydrocarbon molecules. The so-called united atom potentials (UA) introduce groups of atoms like $\mathrm{CH}_{2}$ or $\mathrm{CH}_{3}$ as simple Lennard-Jones sites. This strategy allows a more efficient computation of collective properties in large systems requiring long simulations. There are several UA potentials developed to describe thermodynamic properties of n-alkanes with good performance, for instance the OPLS [4], SKS [5] , TraPPE [6] and the NEP [7]. All atom models (AA), 
being more realistic, are useful for particular applications but the price paid in computer time is unaffordable in many studies involving molecules with complex geometries or large size.

Another common approach is the so-called anisotropic united atom for which Toxvaerd and coworkers have published successive parameterizations (AUA(1) [8], AUA(2) [9], AUA(3) [10]). In this approach the centre of force is displaced by a distance $\delta_{\mathrm{AUA}}$ from the carbon atom to better account for the presence of the hydrogen atoms not explicitly described. In a previous work [11] it was found that the shear viscosity reproduced by different UA and AUA models, analyzed over different thermodynamic states, present important deviations with respect to the experimental data (about $24 \%$ for AUA2, $26 \%$ for SKS2, 30\% for AUA3, 48\% for OPLS [4] and 54\% for TraPPE [12]). In general, all models tend to underestimate the viscosity and to overestimate the self-diffusion coefficient.

The AUA approach has been successfully applied to different families of hydrocarbons, from linear [13], branched [14] and cyclic [15] alkanes and alkenes [16], and to other sulphur ([17], [18]) compounds. In particular, a set of important works have been addressed to aromatics, from benzene ([19], [20]) light [21] and heavy alkyl-benzenes ([22], [23]) or poly-aromatic compounds [24]. This kind of potential represents a good success for prediction of thermodynamic properties with much less computational effort than All Atoms models. However, they have shown their limitations when used to compute transport properties, motivating an additional effort of improvement for the case of the AUA4 model of n-alkane molecules. Nieto-Draghi et al. have recently shown that the dynamical behaviour of the AUA4 model can be easily optimised, by adjusting the energetic barrier of the torsion potential, without changing the thermodynamic accuracy of the original model [25]. In this case the shear viscosity of nalkanes was optimised from 30\% of Absolute Average Deviation (AAD) with the AUA4 model up to $14 \%$ with the new AUA4m model.

Several simulation studies have been done in the past to study relatively long complex branched alkanes in order to obtain thermodynamic [26], conformational [27] and transport [28] properties. Most of the works have been devoted to the analysis of rheological behaviour of shear viscosity under stress for 
pure complex branched alkanes ([29], [30], [31], [32], [33], [34]) and olefins ([35], [36]) lubricants and polymers melts [37]. However, there are only few works on the literature ([11], [38]) that explore the viscosity of small branched alkanes like those encountered in gasoline fuels (i.e. i- $\mathrm{C}_{5}, \mathrm{i}-\mathrm{C}_{7}$ and i- $\mathrm{C}_{8}$ ). The situation is even worse in the case of transport properties of multi-component mixtures of hydrocarbons ([39], [40]).

The main objectives of this work are, on one hand, to test and improve the dynamical behaviour of the AUA4 model developed for branched alkanes [14] and olefins [16]. On the other hand, to present a consistent methodology to describe and simulate thermodynamic and transport properties of complex multi-component mixtures like fuel gasoline. The first objective can be addressed by the improvement of the torsion potential of the different type of branched alkanes (involving torsion around secondary, tertiary and quaternary carbons). The idea is to obtain an AUA model for this kind of hydrocarbons compatible with the AUA4m model for n-alkanes, and use them in simulation of mixtures. In particular, we have compared our simulation results of thermodynamic properties (like liquid density) and transport properties (like shear viscosity) with the available experimental data for 13 different branched alkanes. Similarly, the dynamical behaviour of olefins were also computed and compared with experimental measurements. Concerning the second objective of our work, we describe a consistent method to reduce the experimental composition of a standard gasoline fuel (with more than 200 components obtained with Gas Chromatography (GC)), to a reduced number of chemical compounds adapted for molecular simulation calculations.

The present article is organised as follows: In the next section we review the relevant theoretical and technical details related to our simulations. The following section is devoted to the optimization procedure employed for the improvement of the torsion potential. After that, we present the simulation results and finally, we highlight the main conclusions that can be drawn from this work. 
1

\section{Models and simulation detail \\ Molecular Dynamics calculations}

We have employed a Molecular Dynamics code developed for rigid and flexible molecules (considered linear, branched or cyclic). The equations of motion are integrated through the velocity Verlet algorithm with constrained bonds using of the Rattle algorithm [41]. We have explored the behaviour of different linear, branched and aromatic hydrocarbons at different thermodynamic conditions. Because the main objective of this work is to test the predictive capability of the improved potential, all samples where equilibrated at the desired temperature and pressure through NPT rescaling using a weak coupling bath [42] with long-range corrections [11] for pressure and energy on a one ns run. Unless specified otherwise, the production runs are around $10 \mathrm{~ns}$ for each system. The integration of the equations of motion was performed with a time step of 2 fs and with a cut-off radius of $12.0 \AA$. A Verlet nearest neighbour list was also employed to improve the performance of the simulations. In general, all simulation samples consist of 250 molecules for the systems containing single compound and 500 molecules for the case of mixtures. In all cases the molecules were placed in a cubic box using periodic boundary conditions. Special care has been taken to handle the displacement $\delta_{\mathrm{AUA}}$ of the AUA intermolecular potential model for the computation of the forces and velocities of centre of mass. The reader is referred to previous references for additional information ([8], [9], [10], [13], and [38]). As in our previous works ([20], [25]), the Einstein methodology was employed for the calculation of the shear viscosity of the different systems studied since this approach overcomes the effect of statistical noise observed in theoretically equivalent Green-Kubo formulation $[20,25]$.

\section{Monte Carlo calculations}

We have used the Gibbs Monte Carlo code [43] to perform simulation in the Gibbs ensemble [44] to compute thermodynamic properties of gasoline mixtures at some particular thermodynamic conditions. 
The Monte Carlo moves for rigid bodies are translations and rigid body rotations, transfers [5] and volume changes. For branched and flexible molecules two types of moves have been considered. The first one is partial re-growth with the configurational bias algorithm [5]. As this move is efficient for the end part of alkane chains only [14] it is complemented by internal rotations, in which the positions of a force centre is rotated around the axis of its immediate neighbours on the chain. In the case of transfers, we used a two step statistical bias involving the selection of a suitable location for the centre of mass in a first step and the test of several orientations in a second step [15]. The selected probabilities for the various types of moves were generally 0.3 for translations and rotations, 0.395 for transfers, and 0.005 for volume changes. Most simulations were carried out using a total of 500 molecules. Equilibration periods of $10^{6}$ iterations were followed by at least $10 \times 10^{6}$ steps for production runs where the block averages method have been used to obtain the saturation density and the phase composition.

\section{Intermolecular potential}

The effective dispersion-repulsion interactions between two atoms or united atoms $(i$ and $j$ ) of different molecules are represented by the Lennard- Jones 6-12 equation

$U_{L J}=4 \varepsilon_{i j}\left[\left(\frac{\sigma_{i j}}{r_{i j}}\right)^{12}-\left(\frac{\sigma_{i j}}{r_{i j}}\right)^{6}\right]$

where $\sigma_{i j}$ and $\varepsilon_{i j}$ are the Lennard-Jones interaction parameters between sites $i$ and $j$ on different molecules, and $r_{i j} \equiv\left|\mathbf{r}_{\mathrm{j}}-\mathbf{r}_{\mathrm{i}}\right|$ are the separation distance between sites $i$ and $j$. Cross interactions between centres of force of different type were treated using standard Lorentz-Berthelot combining rules. The electrostatic energy is obtained by summing the pair wise Coulombic interactions between the partial charges belonging to the different molecules (eq. (2)).

$U_{\text {elec }}=\frac{1}{4 \pi \varepsilon_{0}} \sum_{i \neq j} \frac{q_{i} q_{j}}{r_{i j}}$ where $q_{i}$ and $q_{j}$ are the charges of different centres of interaction and $\varepsilon_{0}$ the dielectric constant of vacuum. In both types of simulations (MD and MC), the Ewald Summation technique [45] has been used to treat 
the long range electrostatic interactions with a maximum of 7 vectors on each direction of the reciprocal space and a scaling parameter $\alpha=2 \pi / \mathrm{L}\left(\AA^{-1}\right)$ in the direct space with spherical cut-off of half of the simulation box (L). The bending angle $\theta$ between three adjacent atoms has been described through a harmonic potential,

$$
U_{B}(\theta)=\frac{K_{B}}{2}\left(\cos (\theta)-\cos \left(\theta_{0}\right)\right)^{2}
$$

where $\theta_{0}$ is the bending angle at the equilibrium configuration and $K_{B}$ is the bending constant. In a similar way, when two carbon atoms are separated by three bonds, their interaction is modelled by a torsion potential that depends on the cosine of the dihedral angle $\varphi$,

$$
\cos (\varphi)=-\frac{\left(\mathbf{r}_{i j} \times \mathbf{r}_{j k}\right) \cdot\left(\mathbf{r}_{j k} \times \mathbf{r}_{k l}\right)}{\sqrt{1-\left(\mathbf{r}_{i j} \cdot \mathbf{r}_{j k}\right)^{2}} \sqrt{1-\left(\mathbf{r}_{j k} \cdot \mathbf{r}_{k l}\right)^{2}}}
$$

being $i, j, k$ and $l$ the atoms involved in the torsion angle. The torsion potential for individual linear/branched contributions is then defined as,

$$
U_{t}(\varphi)=\sum_{i=0}^{8} a_{i} \cos ^{i}(\varphi)
$$

where $a_{i}$ are a set of constants. In addition, every two atoms belonging to the same molecule and separated by more than 4 atoms interact through the standard LJ potential described in eq. (1). The intermolecular potential parameters used in this work are given in Table 1.

\section{Optimization of the dynamic behaviour of branched alkanes}

Our previous experience on the optimization of transport properties of n-alkanes reveals that the dynamic behaviour of $n$-alkanes, reflected in the self-diffusion and viscosity coefficients, is governed by the combined effect of the torsion potential and the dispersion repulsion potential at liquid densities [25]. In this previous work we have improved the performance of the AUA4 intermolecular potential to predict 
dynamic properties, keeping the accuracy of the model for equilibrium properties. We have shown that only the torsion potential parameters should be optimized using n-heptane as the reference molecule at liquid conditions. We have then decided to apply a similar approach to improve the dynamic behaviour of the Anisotropic United Atom potential for branched alkanes, modifying the torsion potential for the different types of molecules represented in Figure 1.

In our previous work for n-alkanes two properties were simultaneously considered in the process of optimization: the reorientational dynamics of the internal dipole moment $\mathrm{CH}$ vector from nuclear magnetic resonance (NMR) $\mathrm{C}^{13} \mathrm{~T}_{1}$ spin lattice experiments and the shear viscosity at the same thermodynamic conditions. Unfortunately, we did not find NMR relaxation data for branched alkanes to compare with. $\underline{\text { An }}$ alternative way to obtain this property could be the use of DFT ab initio calculations. However this approach would demand a considerable computational effort in view of the required system sizes and simulation lengths (estimated between 200 to 300 atoms during 15 to 20 ps at least). We have then decided to modify the torsion potential in the same way ar for the AUA4m model. This means that the increment of the energetic barrier for the global torsion potential of molecules at the end and in the middle of the chain should be of the order of $40 \%$ and $15 \%$ respectively. This choice presents the advantage of making small molecules artificially more rigid in order to compensate the influence of hydrogen atoms absent in the AUA representation. Consequently, branched atoms at the end of the chain (i.e. in position 2, for 2methyl hexane) are considered more rigid than atoms that are in the middle of the chain (i.e. in position 3 , for 3-methyl hexane). For longer branched alkanes the friction caused by the hydrogen atoms is less important for the viscosity than in small molecules, since the conformational relaxation plays also an important role in the global dynamical behaviour of the molecules.

We have taken advantage of the link between the torsion barrier of an intramolecular potential and the resulting collective behaviour expressed in transport properties to improve the AUA4 model for branched alkanes. We propose to work in the increment of the energy barrier of the global torsion potential of the 
molecules and not on the individual torsion of a particular branch. This modification is expressed in the following way,

$$
U_{T}^{\text {new }}(\varphi, \theta)=U_{T}^{\text {old }}(\varphi, \theta)+U_{S}(\varphi, \theta)
$$

where $U_{T}^{\text {new }}$ and $U_{T}^{\text {old }}$ are, respectively, the new and original global torsion potentials, and $U_{S}$ is a trigonometric function specific for each type of branched molecule. Here $\varphi$ and $\theta$ represent the dihedral angle of the total torsion and the bending angle separating two adjacent branches. The construction of each potential requires the definition of the angle $\theta$, which we have assumed to be at equilibrium.

Molecule type A. Single branched

In order to obtain the global potential $U_{T}$, two contributions of the branched alkane should be added as can be seen in Figure 1(a). The AUA torsion parameters for this type of molecules are taken from previous works ([14], [46]). Additionally, as can be seen in the Newman representation of Figure 1(b), the bending angle $\theta$ was fixed to $112^{\circ}$ for the single branched alkane,

$$
\begin{gathered}
U_{T}(\varphi, \theta)=c_{0}^{\prime}+c_{1} \cos (\varphi+\theta)-c_{2} \cos (2 \varphi+2 \theta)+c_{3} \cos (3 \varphi+3 \theta)+ \\
c_{0}^{\prime}+c_{1} \cos (\varphi-\theta)-c_{2} \cos (2 \varphi-2 \theta)+c_{3} \cos (3 \varphi-3 \theta) \\
U_{T}(\varphi, \theta)=2 c_{0}^{\prime}+2 c_{1} \cos (\varphi) \cos (\theta)-2 c_{2} \cos (2 \varphi) \cos (2 \theta)+2 c_{3} \cos (3 \varphi) \cos (3 \theta)
\end{gathered}
$$

Equation (8) is used to represent $U_{T}^{\text {new }}$ and $U_{T}^{\text {old }}$ and the trigonometric function $U_{S}$ is defined as follows,

$$
U_{S}(\varphi, \theta)=A s\left[1+\cos (3 \varphi) \sin ^{2}\left(3 \frac{\theta}{2}\right)-\sin ^{2}\left(3 \frac{\theta}{2}\right)\right]
$$

This function guarantees that only the maxima of the global torsion barrier is affected $\left(\varphi \sim 60.73^{\circ}\right)$ and the minima are kept constant as can be seen in Figure 2(a). The coefficient As is then used to increase the height of the energy barrier of $15 \%$ and $40 \%$ in the middle and at the end of the chain. Once the new 
1

global potential $U_{T}^{\text {new }}$ is obtained, we can obtain the $a_{i}$ parameters of the individual torsion potential as expressed in eq (5) by using a simple transformation described in eq. (20) of the Appendix 1. The new parameters of the individual torsion potential are shown in table 2 and in Figure 2(b).

\section{Molecule type B. Double branched}

In order to obtain the global potential $U_{T}$, three contributions of the branched alkane should be added as can be seen in Figure 1(c). The AUA torsion parameters for double branched molecules on the same carbon atom are taken from the work of Martin et al. [47] but adapted for the use of eq (5). As can be seen in the Newman representation of Figure 3(b), the bending angle $\theta$ was fixed to equilibrium value of $109^{\circ}$ for the double branched alkane around the same carbon atom. In this case $U_{T}$ becomes,

$$
\begin{gathered}
U_{T}(\varphi, \theta)=c_{0}^{\prime}+c_{1} \cos (\varphi)-c_{2} \cos (2 \varphi)+c_{3} \cos (3 \varphi)+ \\
c_{0}^{\prime}+c_{1} \cos (\varphi+\theta)-c_{2} \cos (2 \varphi+2 \theta)+c_{3} \cos (3 \varphi+3 \theta)+ \\
c_{0}^{\prime}+c_{1} \cos (\varphi-\theta)-c_{2} \cos (2 \varphi-2 \theta)+c_{3} \cos (3 \varphi-3 \theta) \\
U_{T}(\varphi, \theta)=3 c_{0}^{\prime}+\left(2 c_{1} \cos (\theta)+1\right) \cos (\varphi)-\left(2 c_{2} \cos (2 \theta)+1\right) \cos (2 \varphi)+\left(2 c_{3} \cos (3 \theta)+1\right) \cos (3 \varphi)
\end{gathered}
$$

Equation (11) is used to represent $U_{T}^{\text {new }}$ and $U_{T}^{\text {old }}$ and the trigonometric function $U_{S}$

$U_{S}(\varphi, \theta)=A s\left[\frac{3}{2}+\cos (3 \varphi)\left(\sin ^{2}\left(3 \frac{\theta}{2}\right)-\cos ^{2}\left(3 \frac{\theta}{2}\right)-\frac{1}{2}\right)\right]$

The comparison of the global torsion potentials can be seen in Figure 3(a). The coefficient $A s$ is used to increase the height of the energy barrier of $15 \%$ and $40 \%$ in the middle and at the end of the chain respectively. We repeat the procedure described for the previous type of branched molecules in order to obtain the $a_{i}$ parameters of the individual torsion potential as expressed in eq (5) (conversion between 
coefficients $c_{i}$ and $a_{i}$ is obtained using eq. (20)). The new parameters of the individual torsion potential are shown in table 2 and in Figure 3(b).

\section{Molecule type C. Double branched in adjacent carbons}

The last type of torsion for branched alkane that we have analysed is the double branched structure in adjacent carbons. In other intermolecular potential models such as TraPPE potential [47] or UA-OPLS [4], there is no difference between the torsion potential used for molecules having only one methyl group or two methyl groups branched in adjacent carbon atoms. We have decided here to describe in a precise manner this kind of torsion potential for molecules having the structure 2,3-dimethyl, for instance. We have performed $a b$ initio calculations using the GAUSSIAN98 [48] quantum chemistry code. For 2,3dimethyl butane, a MP2 geometry optimization was performed using sddall basis set to determine the torsional potential function of this molecule for conformations of the dihedral angle in the range between 0 $<\varphi<2 \pi$. This function has been fitted using eq. (5) with $n=4$ in order to obtain the set of parameters for the torsion of type $\mathrm{CH}_{\mathrm{i}}-\mathrm{CH}-\mathrm{CH}-\mathrm{CH}_{\mathrm{i}}$ of the AUA model, which are given in Table 2.

This potential has been validated by comparing the liquid-vapor properties of 2,3-dimethylbutane calculated with this potential and experimental data extract from the DIPPR database [49] (DIPPR, 2005). The rest of intermolecular parameters $\left(\sigma, \varepsilon\right.$, and $\left.\delta_{\mathrm{AUA}}\right)$ are identical to the previous type of branched molecules and described in Table 1. NVT Gibbs ensemble Monte Carlo simulations for the 2,3-dimethyl butane using the new torsion potential have been performed using a standard procedure previously described for other molecules [14]. We computed different thermodynamic properties such as the liquid density, the saturation pressure, and the vaporization enthalpy at $423 \mathrm{~K}$ and our simulation results can be observed in Table 3. We found good agreement with experimental data with an absolute average deviation of $0.7 \%$ for the liquid density, $10.6 \%$ for the saturation pressure and $2.2 \%$ for the enthalpy of vaporization at $423 \mathrm{~K}$.

The procedure employed to fit this kind of intermolecular potentials, using equilibrium thermodynamic properties (either for intra- and inter-molecular parameters), permits a high degree of 
1

accuracy to reproduce thermodynamic properties, but does not guarantee a correct description of the transport properties. That's why we have decided to also modify the torsion potential of this type of branched molecule. Then, in the case of molecules having two branched methyl groups in adjacent carbons, four contributions should be added to the total torsion as can be seen in the Newman representation of Figure 4(b). The bending angle $\theta$ was fixed to equilibrium value of $112^{\circ}$ for the double branched alkane around adjacent carbon atoms. In this case $U_{T}$ becomes,

$$
\begin{gathered}
U_{T}(\varphi, \theta)=2\left[c_{0}^{\prime}+c_{1} \cos (\varphi+\vartheta)-c_{2} \cos (2 \varphi+2 \theta)+c_{3} \cos (3 \varphi+3 \theta)+\right. \\
\left.c_{0}^{\prime}+c_{1} \cos (\varphi-\theta)-c_{2} \cos (2 \varphi-2 \theta)+c_{3} \cos (3 \varphi-3 \theta)\right] \\
U_{T}(\varphi, \theta)=4 c_{0}^{\prime}+4 c_{1} \cos (\varphi) \cos (\theta)-4 c_{2} \cos (2 \varphi) \cos (2 \theta)+4 c_{3} \cos (3 \varphi) \cos (3 \theta)
\end{gathered}
$$

Equation (14) is used to represent $U_{T}^{\text {new }}$ and $U_{T}^{\text {old }}$ and the trigonometric function $U_{S}$

$U_{S}(\varphi, \theta)=A s\left[2+2 \cos (3 \varphi)\left(\sin ^{2}\left(3 \frac{\theta}{2}\right)-\cos ^{2}\left(3 \frac{\theta}{2}\right)\right)\right]$

Finally, the new global potential $U_{T}^{\text {new }}$ (Figure $4(\mathrm{a})$ ) is obtained and the $a_{i}$ parameters can be computed following the procedure employed in the two previous cases. The new parameters of the individual torsion potential are shown in table 2 and in Figure 4(b).

\section{Results}

\section{Evaluation of the optimised potential}

The modified torsion potential was tested on three different molecules at liquid state (1 bar), 2methyl pentane at $273 \mathrm{~K}, 2$,2-dimethyl pentane at $273 \mathrm{~K}$ and 2,3-dimethyl pentane at $303 \mathrm{~K}$. For each molecule the density of the system was determined in NPT calculations at the desired temperature and pressure during $1 \mathrm{~ns}$ run. The resulting density was used to produce a trajectory run of $2 \mathrm{~ns}$ using the canonical Nosé-Hoover [50] NVT ensemble with a coupling constant of $0.1 \mathrm{ps}^{-1}$. All tests were performed 
with 250 molecules and the rest of simulation details (cut-off, long-range corrections, etc) are similar to those described in the methodological section.

\section{Equilibrium distribution and internal dynamics}

The distribution of dihedral angles of molecules of type A, involving the methyl group in position 2 (see Figure 1(a)), for the 2-methyl pentane molecule can be seen in figure 2(c). As expected the increment in the energetic barrier modifies the form of the distribution of molecules around equilibrium configurations, i.e. at values of the dihedral angle $\varphi$ of $0^{\circ}$ and $120^{\circ}$ approximately, however, the distribution of molecules in Gauche/Trans conformations is not affected. For instance, we can observe that the percentage of molecules in Gauche/Trans configurations remains constant in all cases $(41 \%$ / 59\% for AUA4; $41 \%$ / $59 \%$ for AUA4m $(+15 \%)$ and $43 \% / 57 \%$ for AUA4m $(+40 \%))$. The effect of these modifications on the thermodynamic properties of 2-methyl pentane computed with the original AUA4 model and the new one is very small, $<0.3 \%$ of absolute deviation for liquid density, $<3 \%$ for the saturation pressure and $<0.7 \%$ for the vaporisation enthalpy.

The differences in the dihedral angle distribution of molecules of type B, involving two methyl groups in position 2-2 (see Figure 1(c)), for 2,2-dimethyl pentane can be observed in Figure 3(c). In general we observe a correlation between increments of the energetic barrier with the increase of the population of molecules at equilibrium configurations. Again, we observe a constant ratio of Gauche/Trans configurations for this molecule $(31 \%$ / $69 \%$ for AUA4; $32 \%$ / 68\% for AUA4m (+15\%) and 33\% / 67\% for AUA4m $(+40 \%))$. In this case the difference in the behaviour of thermodynamic properties between the original AUA4 model and the new model are $<0.5 \%$ of deviation for liquid density, $<1.7 \%$ for the saturation pressure and $<0.9 \%$ for the vaporisation enthalpy.

Finally, the angle distribution of model type $\mathrm{C}$ involving the two methyl groups in position 2-3 (see Figure 1(e)) for the 2,3-dimethyl pentane can be seen in Figure 4(c). In this particular case, we have observed a very small difference in the Gauche/Trans conformations (18\% / 82\% for AUA4; $21 \%$ / $79 \%$ 
for AUA4m $(+15 \%)$ and $22 \% / 78 \%$ for AUA4m $(+40 \%))$. This fact comes form the small difference $(<5 \%)$ in the position of the minima of the torsion potential observed in Figure 4(b) at about $106^{\circ}$. This fact does not significantly affect the thermodynamic behaviour between the two models to reproduce several thermodynamic properties. For instance, we observe a difference of $0.1 \%, 4.5 \%$ and $0.4 \%$ for the density, saturation pressure and heat of vaporisation respectively between the AUA4 and the AUA4m model for this particular molecule.

We have also analysed the effect of the modification of the torsion potential on the internal dynamical properties of the three different molecules studied. For instance, we have computed the autocorrelation function (ACF) of the dihedral angle (see definition of $\cos (\varphi)$ in eq. (4)), defined as,

$$
C_{i}(t)=\frac{\left\langle\cos \left(\varphi_{i}(t)\right) \cdot \cos \left(\varphi_{i}(0)\right)\right\rangle-\left\langle\cos \left(\varphi_{i}(0)\right)\right\rangle^{2}}{\left\langle\cos ^{2}\left(\varphi_{i}(0)\right)\right\rangle-\left\langle\cos \left(\varphi_{i}(0)\right)\right\rangle^{2}}
$$

where $\varphi_{i}(t)$ is the dihedral angle of a given set $i$ of four neighbouring carbon atoms in the hydrocarbon chain at time $t$. As it can be expected the decay time of the torsion autocorrelation function (defined in eq. (16)) is strongly affected by the modifications of the energetic barriers on the torsion potential. The comparison of the dihedral angle ACF for the different models and torsion potentials tested can be observed in Figure 5. In the case of 2-methyl pentane (Figure 5(a)), we show the torsion concerning the methyl group in position 2. The increase of the barrier strongly affect the relaxation of the molecule around the branched methyl group, as revealed by the decay time obtained by a simple exponential fit of the three different lines, i.e. 36.2 ps for the AUA4 model, 72.78 ps for the AUA4m $(+15 \%)$ and 408.4 ps for the AUA4m (+40\%).

For the 2,2-dimethyl butane (Figure 5(b)), we show the torsion dynamics around the quaternary carbon $\mathrm{C}$ in position 2 (see Figure 1(c)). In this case the variation of the ACF is less pronounced than in the previous case due to the fact that the molecule is slightly smaller. Here we have obtained values for the relaxation time of $20.2 \mathrm{ps}$ for the AUA4 model, $36.3 \mathrm{ps}$ for the $15 \%$ and $115.93 \mathrm{ps}$ for the case of $40 \%$ of increment in the energetic barrier, respectively. For the 2,3-dimethyl pentane (Figure 5(c)), we show the 
torsion dynamics around the tertiary carbon $\mathrm{CH}$ in positions 2 and 3 (see Figure 1(e)). In this case the relaxation times are longer than those of the two other molecules, i.e. 53.4 ps for the AUA4 model and 119.7 ps for the $15 \%$ and 509.8 ps for the $40 \%$ of increment in the energetic barrier, respectively. The order of magnitude of the relaxation times obtained for the torsions using $40 \%$ of increment in the energetic barrier are in perfect agreement with the values obtained in our previous work for the optimization of the AUA4m potential for n-alkane molecules [25]. In this case we expect longer relaxation times due to the presence of the branched atoms. This global agreement in the relaxation times is important since we would like to have a coherent set of parameters to apply the new potential of branched alkanes in mixtures containing lineal n-alkane molecules.

The internal dynamics of hydrocarbons can be analyzed though the internal relaxation times [51] experimentally reported by NMR ${ }^{13} \mathrm{C} T 1$ spin lattice relaxation of the $\mathrm{CH}$ dipole vectors of the different carbon atoms of hydrocarbon molecules. We have computed the internal relaxation of the unitary vector $\hat{\mathrm{e}}_{i}$, describing the displacement $\delta_{\mathrm{AUA}}$ of the AUA intermolecular potential model at different positions inside the hydrocarbon chain. This vector is intended to mimic the geometrical position of the valence electrons of the $\mathrm{CH}_{\mathrm{i}}$ group, which is equivalent to the vector describing the geometrical position of all the hydrogen atoms not explicitly described in this kind of united atom type force field. The rotational correlation time of each vector inside the hydrocarbon chain was computed according to [51],

$\tau_{C_{i}}=\int_{0}^{\infty}\left\langle P_{2}\left(\hat{\mathbf{e}}_{i}(t) \cdot \hat{\mathbf{e}}_{i}(0)\right)\right\rangle d t$

where $P_{2}$ is the Legendre polynomial of second order. As in our previous work for n-alkanes [25] we do not describe the relaxation time of the hydrogen atoms in methyl groups $\left(\mathrm{CH}_{3}\right)$ at the end of the chain. Since the AUA representation uses neighbouring atoms to compute the direction of the $\delta_{\mathrm{AUA}}$ vector, we do not expect that this simplification can match the behaviour of these hydrogen atoms that are more mobile than internal hydrogen atoms due to steric reasons.

The variation of the relaxation time of the $\mathrm{CH}$ vector for the carbon atom at different position inside the chain for the molecules analyzed can be observed in Figure 5. For the case of 2-methyl pentane 
we have computed the values for the $\mathrm{CH}_{\mathrm{i}}$ groups in position 2, 3 and 4 (see Figure 1(a)). In this case we observe how $\tau_{\mathrm{ci}}$ (Figure $\left.5(\mathrm{~b})\right)$ presents a higher value for the $\mathrm{CH}$ vector of the tertiary carbon atom, the one attached to the methyl group in position 2 than the rest of carbon atoms in the molecule (at position 3 and 4). The effect of the increment in the energetic barrier is to increase homogeneously the values of the relaxation times of the $\mathrm{CH}$ vectors analysed, i.e. slowing down the reorientational dynamics of all the internal carbon atoms. For the 2,2-dimethyl butane we have only computed the relaxation of the $\mathrm{CH}$ vector of the $\mathrm{CH}_{2}$ group in position 3 (see Figure 1 (c)) and the results can be observed in Figure 5 (e). In this case the values of $\tau_{\mathrm{ci}}$ are smaller than for the previous molecule, i.e. a faster relaxation. It is interesting to analyse the reorientational time of the $\mathrm{CH}$ vectors for the third type of molecules, the 2,3-dimethyl pentane, in Figure 5(f). The variation of $\tau_{\mathrm{ci}}$ in function of the position of the carbon atom inside the chain shows a maximum value for the $\mathrm{CH}$ vector in position 3. This fact is expected since the torsion involving the two carbon atoms at position 2 and 3 are not symmetric with respect to the end of the chain, i.e. the atom in position 3 is involved in more torsions than the atom in position 2 . It would be interesting to compare these relaxation times with $\mathrm{NMR}{ }^{13} \mathrm{C}$ spin lattice experimental data of branched alkanes at the same thermodynamic conditions in order to validate our calculations. However, we can observe that the values of the reorientational time $\tau_{\mathrm{ci}}$ for the three different branched molecules analysed in this work show are of the same order of magnitude with those observed for the case of n-alkane molecules [25].

\section{Shear viscosity of branched alkanes}

Simulation results for the density and shear viscosity of different short branched alkane molecules (C5C7) computed using both AUA4 and AUA4m models are compared with the available experimental data in Table 4 ([49], [52], [53], [54]). We have included in our comparison different molecules representing the three types of molecules optimised in this work (A, B, C). In general, for branched molecules of type A, we observe an average deviation (AAD) of about $24 \%$ AUA4 and $18 \%$ for the AUA4m. The accuracy obtained using the new potential on this kind of molecules is in perfect agreement with the deviation 
observed for small linear n-alkane molecules with the AUA4m model [25] ( 19\% of AAD for n-pentane). The liquid density is reproduced with high accuracy by both models (less than $1 \%$ ).

In the case of molecules with two branched methyl groups on the same carbon (molecules of type B), we observe that the AUA4m model does not behaves as well as in the previous case. We obtain an AAD of 43\% and $38 \%$ for the AUA4 model and AUA4m model, respectively. The density is well reproduced by the models with an $\mathrm{AAD}<1 \%$. We observe that the AUA representation shows important limitations to reproduce the experimental shear viscosity of small molecules with "star" forms, like the 2,2-dimethyl butane due to the absence of explicit hydrogen atoms in the model. In this particular molecule, the presence of three methyl groups plays an important role on the friction between molecules. This fact becomes evident if we compare the difference in viscosity between three branched C6 isomer molecules but having different number and position of methyl groups in Figure 6(a). For instance, we can see how the AUA model is not able to follow the trend observed in the experimental data at $273 \mathrm{~K}$ and 1 bar (212 $\mu \mathrm{Pa}$.s for the 2-methyl pentane, $395 \mu \mathrm{Pa}$.s for the 3-methyl pentane and $477 \mu \mathrm{Pa}$.s for the 2.2-dimethyl butane). If we increase the size of the chain, the importance of the hydrogen atoms of the methyl groups becomes less important for the viscosity, since the effect of the torsion potential becomes also important. This fact can be clearly seen in Figure 6(b), when comparing the same type of molecules than in Figure 6(a) but slightly longer. In this case only the new AUAm model follows the change in the shear viscosity with the number and position of methyl groups inside of the chain observed experimentally.

For the last type of molecules (type C), we have obtained an AAD of $20 \%$ for the AUA4 and $15 \%$ for the AUA4m. We have compared our simulation results with experimental data at different pressures up to 600 bars at two different isotherms $(303.25 \mathrm{~K}$ and $333.15 \mathrm{~K})$ in Table 4 . We observe a good agreement between the experimental data and the results obtained with the optimised AUA4m model. It is interesting to compare the behaviour observed between this type of molecules, presenting two methyl groups at adjacent carbon positions, and the previous group (B). Here the effect of increasing the energetic barrier increases the accuracy of the viscosity of 2,3-dimethyl pentane of about $25 \%$ for the new model with 
3

respect to the original one. Again we have obtained an $\mathrm{AAD}$ of $<2 \%$ for the liquid density for both models.

The comparison of the simulation results and the available experimental data ([55], [56]) for the liquid density and the shear viscosity of different C8-C10 branched molecules can be seen in Table 5. In this case, we observe a better performance of both potentials (AUA4 and AUA4m) than in the case of smaller molecules (C5-C7). Here, the optimised AUA4m potential presents a global AAD of 1.4\%, $18.8 \%$ and 7.9\% for molecules of type (A), (B) and (C), respectively (the original AUA4 model presents an AAD of $9.1 \%, 23 \%$ and $25 \%$, respectively). This behaviour is expected since the optimisation of the torsion potential works better for longer alkane chains [25] as can be seen in Figure 6(c). Here, we have computed the variation of the shear viscosity at $298 \mathrm{~K}$ and 1 bar with the chain length for molecules having a methyl group in position 2.

The comparison of the global AAD between the AUA4 model and the AUA4m model for the three different types of molecules studied here can be observed in Figure 7. In general we obtain a global performance of about $16.5 \%$ of AAD for the shear viscosity with the new AUA4m model, which is less than the $24 \%$ obtained with the original AUA4 model.

Shear viscosity of olefins

The dynamical behaviour of olefins reproduced by the AUA4 model has not been tested in the past. We have decided to do it here since our objective is to perform a molecular simulation of fuel gasoline, which may contains up to $10 \%$ of this kind of hydrocarbons. The AUA4 model of olefins developed by Bourasseau et al. [16] presents a good performance reproducing thermodynamic properties $(<1.3 \%$ for liquid density, $<2.1 \%$ for the enthalpy of vaporisation and $<11 \%$ for the saturation pressure). The intermolecular potential parameters can be seen in Table 1 and Table 2. Olefins are more rigid than nalkane molecules, that's why our preliminary tests, trying to modify the torsion parameter, reveal that this kind of molecule is insensitive to this procedure. We have then decided to keep unchanged the parameters 
of the original AUA4 model. The comparison between the available experimental data ([55], [49]) and our simulation results for the density and the shear viscosity for small olefins such as 1-butene, trans-2-butene, 1-hexene and trans-2-hexene can be observed in Table 6. We have obtained a good agreement between the experimental data and the results computed with the AUA4 model with an AAD of $11.9 \%$ for the shear viscosity and less than $0.6 \%$ for the liquid density.

\section{Molecular simulation of fuel gasoline}

The development of a new generation of flexi-fuel motor engines, working at blend composition of gasoline and bio-ethanol requires the knowledge of thermophysical properties of complex mixtures at different thermodynamic conditions. A systematic campaign of experimental data acquisition on these cases can be expensive. Molecular simulation can be used as a good alternative to obtain these properties, however, the description of real complex mixtures such as those present in fuels represent a great challenge. The problem comes from the fact that real fuels may have more than 200 chemical compounds grouped in several families of hydrocarbons, i.e. n-alkanes (also known as normal paraffins), branched alkanes, cyclic alkanes (naphtens), olefins, aromatics and other chemical species such as oxygenated and sulphur compounds. Following previous experience on simulating complex mixtures such as natural condensate gases [57], we have reduced the number of compounds to 12 in order to perform molecular simulations. We propose in this work a consistent methodology to represent the composition of standard gasoline fuels by the use of limited amount of compounds. To achieve this simplification we have applied

a lumping method called "dynamical cluster" [58]. This method is commonly applied in the oil industry to

Deleted: nuées dynamiques simplify the thermodynamic representation of complex streams by a reduced number of "pseudo components". These components do not necessarily correspond to an exact physical real chemical compound. However, in our particular case we have done an additional final step to "match" (also known as delumping) as accurately as possible the hypothetical pseudo component with real chemical species in order to perform molecular simulations on a specific mixture. 
Method for gasoline fuel lumping

As mentioned before the aim of a lumping method is to represent a fuel oil with a reduced number of components without losing too much information on this fuel. One of the methods used for this purpose is to consider all the components of the detailed composition of the fuel and then regroup them into a given number of pseudo components. Properties of each pseudo component are then estimated as function of the properties of initial components (i.e. the real detailed composition) present in the corresponding pseudo component.

Obtaining a detailed composition of the fuel

Main properties of each component of the fuel such as critical properties (temperature Tc, pressure Pc at least), molecular weight $\mathrm{Mw}$, acentric factor $\omega$, carbon to hydrogen ratio $\mathrm{C} / \mathrm{H}$... etc) must be known. In this case we have used a standard gasoline. This is a typical standard gasoline fuels used in car engines where a Gas Chromatography analysis, using an adapted Carburane ${ }^{\circledR}$ analysis tools ([59], [60]), allows to identify very precisely all the components of the fuel (more than 250). The volume distribution of the main chemical species and the size of hydrocarbons chains can be observed in Table 7. The DIPPR thermodynamic properties data base [49] is then used to associate as many as possible components with their thermodynamic properties. In this work it was decided to group, in a first lumping step, the components of a same chemical family (n-paraffin, iso-paraffin, aromatics, naphtens ... etc.) and same number of carbon in order to reduce the number of initial components and to avoid components without all their thermodynamic properties precisely defined. It is thus possible to go from more than 250 components identified with a group contribution analysis to about 50 real components without losing much information. If the detailed composition is not known completely (for example with standard Diesel fuels and heavy fuel oils for which almost $15 \%$ (molar composition) of the components are $\mathrm{C} 15+$ and they are not identified 
with a classical gas chromatography analysis) then the detailed composition is obtained with a "breakdown" accomplished on a True Boiling Point (TBP) curve [61]. The complete procedure of the lumping method can be observed in the Appendix 2.

\section{Lumping of a standard non oxygenated gasoline}

We have decided to use 12 pseudo components for which values of Tc, Pc, Vc, $\omega$, molecular weight, $\mathrm{C}$ number and $\mathrm{C} / \mathrm{H}$ ratio are obtained during the lumping procedure. We have not included the oxygenated compounds in our "hypothetical gasoline" since these additives of gasoline presents a global composition of less than $3 \%$, and because we will study the influence of these compounds in a future work. The result of the lumping methodology applied to the experimental composition of gasoline and the assignment of chemical compounds for each pseudo component can be observed in Table 8 . The physical properties obtained in the lumping procedure allow us to assign a chemical compound to each pseudo component. This ideal gasoline contains about $36 \%$ of aromatics, $16 \%$ of normal paraffins, $30 \%$ of isoparaffins (with almost half of the composition concerns the 2,2,4-threemethyl-pentane or iso-octane) and $16 \%$ of olefins. For this particular choice cyclic (saturated) alkanes are not represented, however this is not a serious problem due to the low concentration of this kind of compounds in the real gasoline (less than $5 \%)$

In order to check, in a qualitative way, the assignment of components (or delumping) we have computed a Monte Carlo simulation in the Gibbs ensemble with the global composition, the pressure and the temperature fixed at $400 \mathrm{~K}$ and 5 bar, respectively. The results are shown in table 8 and compared with the composition obtained with the pseudo components at the same thermodynamic conditions. We observe a global agreement in the composition of both phases.

Simulation of viscosity of gasoline fuel 
The different chemical compounds of our synthetic gasoline are described by the three different types of AUA intermolecular potentials for which its dynamical behaviour was checked at different thermodynamic conditions. The n-alkanes and branched alkanes are treated by the new torsion potential of the AUA4m model developed in this work and in ref [25]. Olefins are described using the AUA4 model developed in ref [16] and our calculation on the shear viscosity reveal that this potentials are accurate enough to be used without modifications. Aromatics are represented by a recent ch-AUA4 model that includes the electrostatic interactions of this kind of compounds ([20], [21], [62]). In this case, we have verified the dynamical behaviour computing the shear viscosity and the density of the 1,2,4-thrimethyl benzene at $298.15 \mathrm{~K}$ and $400 \mathrm{~K}$ at saturation in Table 6 . We have obtained an AAD of $0.35 \%$ for the liquid density and $2.4 \%$ for the shear viscosity. After this verification of the validity of the different chemical compounds used in our model gasoline we are able to describe its dynamical behaviour with confidence.

According to international standards, the shear viscosity of a gasoline must be between $370 \mu \mathrm{Pa} . \mathrm{s}$ and $440 \mu$ Pa.s and the liquid density between $694 \mathrm{~kg} / \mathrm{m}^{3}$ and $794 \mathrm{~kg} / \mathrm{m}^{3}$ at $293 \mathrm{~K}$ at ambient pressure ([63], [64]). We have performed molecular dynamics simulations in the NPT ensemble using the composition obtained in Table 8 to compute the shear viscosity and density of our gasoline model at $293.15 \mathrm{~K}$ and 1 bar and at $313 \mathrm{~K}$ and 1 bar. We have obtained a shear viscosity of $350.1 \pm 30 \mu$ Pa.s and a liquid density of $746.9 \pm 0.2 \mathrm{~kg} / \mathrm{m}^{3}$ at $293 \mathrm{~K}$ and a viscosity of $285.0 \pm 20 \mu \mathrm{Pa} . \mathrm{s}$ and a liquid density of $728.1 \pm 0.3 \mathrm{~kg} / \mathrm{m}^{3}$ at $313 \mathrm{~K}$. As can be observed in Table 8, our simulation results are in agreement with the accepted range for the value of the density and slightly lower for the value of the shear viscosity (approximately $5.7 \%$ of AAD with respect to the lower limit of the viscosity range) at $293.15 \mathrm{~K}$ In addition, we have used correlation equation of Lohrenz et al. [66] (LBC), which is well adapted to describe hydrocarbon mixtures, to compare with our simulation results in Table 7 . We can observe a reasonable agreement between our calculations and the results obtained with the LBC correlation. It is important to remark that this type of equation is useful at near ambient conditions; however, they can not be applied to estimate the viscosity of fuels at extreme pressure under injection conditions like the ones encountered in motor engines. Finally,

\begin{tabular}{|l|}
\hline Deleted: 405,4 \\
Deleted: 1 \\
\hline Deleted: 747.7 \\
Deleted: 300.2 \\
Deleted: 729.05
\end{tabular}

Deleted: for both properties (density and viscosity)

Deleted: and, also with other experimental measurements on synthetic gasoline fuels [65].

Deleted: good 
we have estimated the shear viscosity of our fuel mixture at $313,15 \mathrm{~K}$ from ambient pressure up to 2500 bar and the results can be observed in Table 8 .

\section{Conclusions}

The Anisotropic United Atom (AUA4) model for branched alkanes was optimised in order to better reproduce dynamical properties such as the shear viscosity by means of an increment of the energetic barriers of the torsion potential. The new potential (AUA4m) presents a general dynamic behaviour which is compatible with the AUA4m model for n-alkane molecules [25] and preserves the accuracy achieved for thermodynamic properties in the AUA(4) model for the density, vapour pressure, enthalpy of vaporisation and the percentage of molecules in trans/gauche conformation. The improvement on the shear viscosity was validated by a systematic comparison of our simulation results on 13 different types of molecules with the available experimental data at different temperatures and pressures. In general, we observe that the new potential has an AAD of about $16.5 \%$, which is substantially lower than the $24 \%$ obtained with the original AUA4 model. Our simulation results on olefin hydrocarbons reveal that the AUA4 model is accurate enough to reproduce experimental shear viscosity data with an AAD of $12 \%$.

A consistent lumping methodology has been applied to simplify the composition of different chemical species present in real fluids like fuel gasoline. The resulting synthetic gasoline composition was then represented by the AUA model for different chemical species (i.e. n-alkanes, branched alkanes, olefins and aromatics) to perform molecular simulations. The simulation results of the shear viscosity of the synthetic gasoline are in good agreement with the experimental data and correlation estimation of shear viscosity at ambient conditions. Simulations were then extended to predict the shear viscosity of a model gasoline at extreme pressure conditions.

The present work represents a good example of the potentialities of the application of molecular simulation techniques to challenging problems encountered in industrial applications. The success of this 


\section{Page 25 of 57}

contribution relies on the development of transferable and accurate intermolecular potentials and simulation methods, able to predict thermo physical properties of real fluids in a wide range of thermodynamic conditions.

\section{Acknowledgements}

The authors would like to thank Philippe Ungerer for fruitful discussions about the liquid-vapour simulations of complex mixtures. In addition, we would like to thank Pascal Mougin and Nicolas Ferrando for their help in the use of the correlative models and Rafael Lugo for the description of physical properties of gasoline fuels.

\section{Appendix}

\section{Expressions of torsion potential}

There are different trigonometric expressions to describe the torsion potential. For instance, eq. (5) can be expressed as,

$$
U_{t}(\varphi)=\sum_{i=0}^{4} a_{i} \cos ^{i}(\varphi)=a_{0}+\frac{a_{2}}{2}+\left[a_{1}+3 \frac{a_{3}}{4}\right] \cos (\varphi)+\frac{a_{2}}{2} \cos (2 \varphi)+\frac{a_{3}}{4} \cos (3 \varphi)
$$

here, the number of parameters $a_{i} i>4$ are zero for the case of branched alkanes. We can compare the right hand side of eq. (18) with the standard form of the torsion potential in Fourier series,

$a_{0}+\frac{a_{2}}{2}+\left[a_{1}+3 \frac{a_{3}}{4}\right] \cos (\varphi)+\frac{a_{2}}{2} \cos (2 \varphi)+\frac{a_{3}}{4} \cos (3 \varphi)=c_{0}+c[1+\cos (\varphi)]+c_{2}[1-\cos (2 \varphi)]+c_{3}[1+\cos (3 \varphi)]$

Then, in the case of our optimisation, we can convert coefficients $c_{i}$ on $a_{i}$ and vice versa with the following matrix, 
1

$$
\left(\begin{array}{c}
c_{0} \\
c_{1} \\
c_{2} \\
c_{0}
\end{array}\right)=\left(\begin{array}{cccc}
1 & -1 & 1 & -1 \\
0 & 1 & 0 & 3 / 4 \\
0 & 0 & -1 / 2 & 0 \\
0 & 0 & 0 & 1 / 4
\end{array}\right) *\left(\begin{array}{l}
a_{0} \\
a_{1} \\
a_{2} \\
a_{3}
\end{array}\right)
$$

\section{Regroup initial components into pseudo components: Lumping.}

The method used in this work is the so called lumping by "dynamical cluster" [58]. Main stages are given below:

a) A number $n$ of pseudo components (or classes) is chosen.

b) $n$ major components of the detailed composition are chosen as initial centres.

c) Calculation of normalized properties Prop $\mathrm{N}_{\mathrm{ik}}$ of each component $i$ and property $\mathrm{k}$ according to,

$$
\operatorname{PropN}_{i k}=\frac{\operatorname{Prop}_{i k}-\operatorname{Min}\left(\operatorname{Prop}_{i k}, x\right)}{\operatorname{Max}\left(\operatorname{Prop}_{i k}, x\right)-\operatorname{Min}\left(\operatorname{Prop}_{\mathrm{ik}}, \mathrm{x}\right)}
$$

where $\operatorname{Min}\left(\operatorname{Prop}_{\mathrm{ik}}, \mathrm{x}\right)$ and $\operatorname{Max}\left(\operatorname{Prop}_{\mathrm{i}}, \mathrm{x}\right)$ are respectively the minimum and maximum values of the $k^{\text {th }}$ property among the $\mathrm{x}$ components $i$ of the detailed composition. This calculation modifies all the properties to be in the range 0 to 1 and ensure that all the properties have the same weight. Most used properties are ( $\mathrm{Tc}, \mathrm{Pc}, \mathrm{Vc}, \mathrm{Mw}, \omega$, and $\mathrm{C} / \mathrm{H}$ ratio).

d) Each component is allocated to the nearest centre. To do so, distances of each component (i) to all the centres (c) are calculated as follow:

$$
\mathrm{d}_{\mathrm{ic}}=\sum_{\mathrm{k}=1}^{\mathrm{NP}} \mathrm{P}_{\mathrm{k}}\left|\operatorname{PropN}_{\mathrm{ik}}^{2}-\operatorname{PropN}_{\mathrm{ck}}^{2}\right|
$$


where NP is the number of properties to be used, $\operatorname{PropN}_{\mathrm{ik}}$ is the $k^{\text {th }}$ normalized property of component $i$, and $\mathrm{P}_{\mathrm{k}}$ is the weight the user wants to apply on a specific property. In this work $\mathrm{P}_{\mathrm{k}}$ will be equal to 0 or 1 (if one property is used or not in the determination of $\mathrm{d}_{\mathrm{ic}}$ ).

e) Centres (c) of all the classes are then calculated with molar fraction xi and properties PropN $\mathrm{i}_{\mathrm{ik}}$ of components included in the class :

$\operatorname{PropN} N_{c k}=\frac{\sum \mathrm{x}_{\mathrm{i}} \operatorname{PropN}_{\mathrm{ik}}}{\sum \mathrm{x}_{\mathrm{i}}}$

f) These centres (c) are considered as new centres of the $\mathrm{n}$ classes. New distances as obtained in stage d) are then calculated and an iterative calculation begins. The calculation stops when no component changing classes from one stage to the next one.

Estimate properties of pseudo components:

The procedure to determine the physical properties of each pseudo component is resumed here and in Figure 8,

a) Properties independent of temperature such as Tc, Pc, Vc, Mw, $\omega$, number of carbon atoms in the molecule and number of hydrogen atoms $\left(\text { Prop }_{\mathrm{k}}\right)_{\mathrm{pseudo} i}$ ) of each pseudo component are estimated from corresponding properties of initial components being part of the pseudo component:

$\operatorname{Prop})_{\text {Pseudo } i}=\frac{\sum_{\mathrm{j} \in \mathrm{i}} \mathrm{x}_{\mathrm{j}} \operatorname{Prop}_{\mathrm{jk}}}{\sum_{\mathrm{j} \in \mathrm{i}} \mathrm{x}_{\mathrm{j}}}$

Critical volume $\left.\mathrm{V}_{\mathrm{c}}\right)_{\text {pseudo } i}$ of each pseudo component $i$ is estimated with a different equation : 
1
$\left.V_{c}\right)_{p s e u d o i}=\frac{\sum_{j \in i} \sum_{k \in i} x_{j} x_{k}\left\{\frac{\left.\left.\left[V_{c}\right)_{j}\right]^{1 / 3}+\left[V_{c}\right)_{k}\right]^{1 / 3}}{2}\right\}^{3}}{\sum_{i \in c} x_{j} x_{k}}$

where $x_{j}$ is the molar fraction of the initial component $j$ and $\left.\mathrm{V}_{\mathrm{c}}\right)_{j}$ is the critical volume of the initial component $\mathrm{j}$ (part of the pseudo i).

The critical compressibility factor Zc) $)_{\text {pseudo } i}$ of pseudo $i$ is estimated with the equation defining this factor :

$\left.Z_{\mathrm{c}}\right)_{\text {pseudo i }}=\frac{\left.\left.\mathrm{P}_{\mathrm{c}}\right)_{\text {pseudo i }} \mathrm{V}_{\mathrm{c}}\right)_{\text {pseudo } \mathrm{i}}}{\left.\mathrm{R} \mathrm{T} \mathrm{T}_{\mathrm{c}}\right)_{\text {pseudo } \mathrm{i}}}$

The Normal Boiling Point (NBP) temperature and the molar volume at NBP are estimated with the equation of state of Peng and Robinson [67] using the necessary properties defined above (Tc, Pc, Vc, Mw, $\omega)$.

\section{Bibliography}

[1] Regulation EC No 715/2007 of the European Parliament and of the council, "on type approval of motor vehicle respect to emissions from light passenger and commercial vehicles (Euro 5 and Euro 6) and on access to vehicle repair and maintenance information". http://www.eur-lex.europa.eu

[2] Mehrotra, A. "Generalized one-parameter viscosity equation for light and medium liquid hydrocarbons", J. Eng. Chem. Res. 30 (1991), pp. 1367-1372.

[3] Marano, J. J., Holder, G. D. "A general equation for correlating the thermophysical properties of nparaffins, n-olefins, and other homologous series. 3. Asymptotic behaviour correlations for thermal and transport properties". Ind. Eng. Chem. Res. 36 (1997), pp. 2399-2408.

[4] Jorgensen, W., Madura, J. D., and Swenson, C. J. "Optimized intermolecular potential functions for liquid hydrocarbons " J. Am. Chem. Soc. 106 (1984), pp. 6638-6646.

[5] Smit, B., Karaboni, S., and Siepmann, J. I. "Computer simulations of vapor-liquid phase equilibria of n-alkanes" J. Chem. Phys. 102 (1995), pp. 2126-2140.

[6] Martin, M. G., and Siepmann, J. I. "Transferable Potentials for Phase Equilibria. 1. United-Atom Description of n-Alkanes " J. Phys. Chem. B 102 (1998) pp. 2569-2577.

[7] Nath, S. A., Escobedo, F. A. and de Pablo, J. J. "On the simulation of vapor-liquid equilibria for alkanes" J. Chem. Phys. 108 (1998), pp. 9905-9911. 
[8] Toxvaerd, S. "Molecular dynamics calculation of the equation of state of alkanes" J. Chem. Phys. 93 (1990), pp. 4290-4295.

[9] Padilla, P., and Toxvaerd, S. "Self-diffusion in n-alkane fluid models" J. Chem. Phys. 94 (1991), pp. $5650-5654$.

[10] Toxvaerd, S. "Equation of state of alkanes II" J. Chem. Phys. 107 (1997), pp. 5197-.

[11] Dysthe, D., Fuchs, A. H., and Rousseau, B. "Fluid transport properties by equilibrium molecular dynamics. III. Evaluation of united atom interaction potential models for pure alkanes" J. Chem. Phys. 112 (2000), pp. 7581-7590.

[12] Siepmann, J. I., Martin, M. G., Mundy, C. J., and Klein, M. L. "Intermolecular potentials for branched alkanes and the vapour-liquid phase equilibria of n-heptane, 2-methylhexane, and 3-ethylpentane" Mol. Phys. 90 (1997), pp. 687-694.

[13] Ungerer, P., Beauvais, C. , Delhommelle, J., Boutin, A., Rousseau, B., and Fuchs, A. H. "Optimization of the anisotropic united atoms intermolecular potential for n-alkanes" J. Chem. Phys. 112 (2000), pp. 5499-5510.

[14] Bourasseau, E.; Ungerer, P.; Boutin, A.; and Fuchs, A. H. "Monte Carlo simulation of branched alkanes and long chain n-alkanes with Anisotropic United Atoms intermolecular potential" Mol. Sim. 28 (2002), pp. 317-336.

[15] Bourasseau, E.; Ungerer, P.; and Boutin, A. "Prediction of Equilibrium properties of cyclic alkanes by Monte Carlo simulation-New Anisotropic United Atoms intermolecular potential-New transfer bias method". J. Phys. Chem. B 106 (2002), pp. 5483-5491.

[16] Bourasseau, E., Haboudou, M., Boutin, A., and Fuchs, A. "New optimization method for intermolecular potentials: Optimization of a new anisotropic united atoms potential for olefins: Prediction of equilibrium properties". J. Chem. Phys. 118 (2003), pp 3020-3034.

[17] Delhommelle, J.; Tschirwitz, C.; Ungerer, P.; Granucci, G.; Millie, P.; Pattou, D.; and Fuchs, A. H. "Derivation of an Optimized Potential Model for Phase Equilibria (OPPE) for Sulfides and Thiols" $J$. Phys. Chem. B 104 (2000), pp. 4745-4753.

[18] Perez-Pellitero, J.; Ungerer, P.; and Mackie, A. D. "An Anisotropic United Atoms (AUA) Potential for Thiophenes" J. Phys. Chem. B 111 (2007), pp. 4460-4466.

[19] Contreras-Camacho, R. O.; Ungerer, P.; Boutin, A.; and Mackie, A. D. "Optimized Intermolecular Potential for Aromatic Hydrocarbons Based on Anisotropic United Atoms. 1. Benzene" J Phys. Chem. B 108 (2004), pp. 14109-14114.

[20] Bonnaud, P., Nieto-Draghi, C., and Ungerer, P. "Anisotropic United Atom model including the electrostatic interactions of benzene", J. Chem. Phys. B 111 (2007), pp 3730-3741.

[21] Nieto-Draghi, C., Bonnaud, P. and Ungerer, P. "Anisotropic United Atom model including the electrostatic interactions of methyl-benzenes. I. Thermodynamic and Structural Properties", J. Chem. Phys. C 111 (2007), pp. 15686-15699.

[22] Ahunbay, M. G.; Kranias, S.; Lachet, V.; and Ungerer, P. "Prediction of thermodynamic properties of heavy hydrocarbons by Monte Carlo simulation" Fluid Phase Equilib. 224 (2004), pp.73-81.

[23] Contreras-Camacho, R. O.; Ungerer, P.; Ahunbay, M. G.; Lachet, V.; Perez-Pellitero, J.; and Mackie, A. D. "Optimized Intermolecular Potential for Aromatic Hydrocarbons Based on Anisotropic United Atoms. 2. Alkylbenzenes and Styrene" J. Phys. Chem. B 108 (2004), pp. 14115-14123.

[24] Ahunbay, M. G.; Perez-Pellitero, J.; Contreras-Camacho, R. O.; Teuler, J. M.; Ungerer, P.; Mackie, A. D.; and Lachet, V. "Optimized Intermolecular Potential for Aromatic Hydrocarbons Based on Anisotropic United Atoms. III. Polyaromatic and Naphthenoaromatic Hydrocarbons" J. Chem. Phys B. 109 (2005), pp. 2970-2976.

[25] Nieto-Draghi, C.; Ungerer, P.; and Rousseau, B. "Optimisation of the anisotropic united atoms intermolecular potential for n-alkanes: Improvement of transport properties" J. Chem. Phys. 125 (2006), No. 044517. 
[26] Bousasseau, E., Sawaya, T., Mokbel, I., Jose, J., and Ungerer, P. "Measurements and prediction of vapour pressures of 2,6,10,14-tetramethylpentadecane (pristane). Experimental and Monte Carlo simulation results" Fluid Phase Equilib. 225 (2004), pp. 49-57.

[27] Lahtela, M., Pakkanen, T.A., and Nissfolk, F. "Molecular dynamics study of the conformational properties of branched alkanes", J. Phys. Chem. A 101 (1997), pp. 5949-5952.

[28] Mondello, M., and Grest, G. "Molecular dynamics of linear and branched alkanes". J. Chem. Phys. 103 (1995), pp. 7156-7165.

[29] Khare, R., de Pablo, J., and Yethiraj, A. "Rheological, thermodynamic, and structural studies of linear and branched alkanes under shear". J. Chem. Phys. 107 (1997), pp. 6956-6964.

[30] Lee, S.H. "The rheology of 6-propyl duodecane and 5-butyl nonane by non-equilibrium molecular dynamics simulations". Mol. Sim. 22 (1999), pp. 271-284.

[31] Moore, J. D., Cui, S. T., Cochran, H.D., and Cummings, P. T. "Rheology of lubricant basestocks: A molecular dynamics study of $\mathrm{C}_{30}$ isomers". J. Chem. Phys. 113 (2000), pp. 8833-8840.

[32] McCabe, C., Cui, S., Cummings, P. T., Gordon, P. A., and Saeger, R. "Examining the rheology of 9octylheptadecane to giga-pascal pressures". J. Chem. Phys. 114 (2001), pp. 1887-1891.

[33] McCabe, C., Manke, C. W., and Cummings, P. T. "Predicting the Newtonian viscosity of complex fluids from high strain rate molecular simulations". J. Chem. Phys. 116 (2002), pp. 3339-3342.

[34] Cui, S. T., Cummings, P. T., Cochran, H. D., Moore, J. D., and Gupta, S. A. "Nonequilibrium molecular dynamics simulation of the rheology of linear and branched alkanes". Int. J. Thermophys. 19 (2004), pp. 449-459.

[35] Kioupis, L. I., and Maginn, E. J. "Molecular simulation of poly-alpha-olefin synthetic lubricant: Impact of molecular architecture on performance properties". J. Phys. Chem. B 103 (1999), pp. 1078110790 .

[36] Kioupis, L. I., and Maginn, E. J. "Impact of molecular architecture on the high-pressure rheology of hydrocarbon fluids". J. Phys. Chem. B 104 (2000), pp. 7774-7783.

[37] Jabbarzadeh, A., Atkinson, J. D., and Tanner, R. I. "Effect of molecular shape on rheological properties in molecular dynamics simulation of Star, H, Comb, and linear polymer melts". Macromol. 36 (2003), pp. 5020-5031.

[38] Dysthe, D. K., Fuchs, A. H., and Rousseau, B. "Fluid transport properties by equilibrium molecular dynamics. I. Methodology at extreme fluid states". J. Chem. Phys. 110 (1999), pp. 4047-4059.

[39] Dysthe, D. K., Fuchs, A. H., and Rousseau, B. "Prediction of fluid mixture transport properties by molecular dynamics". Int. J. of Thermophys. 19 (1998), pp. 437-448.

[40] Dysthe, D. K., Fuchs, A. H., Rousseau, B., and Durandeau, M. "Fluid Transport properties by equilibrium mlecular dynamics. II. Multicomponent systems". J. Chem. Phys. 110 (1999), pp. 4060-4067. [41] Andersen, H. C. "Rattle: A "velocity" version of the shake algorithm for molecular dynamics calculations" J. Comput. Phys 52 (1983), pp. 24-34.

[42] Berendsen, H. J. C., Postma, J. P. M., van Gunsteren, W. F., Di Nola, A., and Haak, J. R. "Molecular dynamics with coupling to an external bath" J. Chem. Phys. 81 (1984), pp.3684-3690.

[43] Ungerer, P., Nieto-Draghi, C., Lachet, V. Wender, A., di Lella, A., Boutin, A., Rousseau, B., and Fuchs, A. "Molecular simulation applied to fluid properties in the oil and gas industry", Mol. Sim. 33 (2007), pp. 287-304

[44] Panagiotopoulos, A. Z. "Direct determination of phase coexistence properties of fluids by Monte Carlo simulation in a new ensemble" Mol. Phys. 61 (1987), pp. 813-826.

[45] Ewald, PP. "Die Berechnung optischer und elektrostaticher gitterpotentiale". Ann. Phys. 64 (1921), pp. 253-287.

[46] Vlugt, T.J.H, Krishna R. and Smit, B. "Molecular Simulations of Adsorption Isotherms for Linear and Branched Alkanes and Their Mixtures in Silicalite ", J. Phys. Chem B 103 (1999), 1102-1118. 
[47] Martin G. and Siepmann, J. I. "Novel Configurational-Bias Monte Carlo Method for Branched Molecules. Transferable Potentials for Phase Equilibria. 2. United-Atom Description of Branched Alkanes " J. Phys. Chem. B 103 (1999), pp. 4508-4517.

[48] Frisch M.J., Trucks G.W., Head-Gordan M., Gill P.M.W., Wong M.W., Foresman J.B., Johnson B.G., Schlegel H.B., Robb M.A., Replogle E.S., Andres J.L., Raghavachiri K., Binkley J.S., Gonzalez C., Marin R.L., Fox D.J., Defrees D.J., Baker J., Steward J.J.P., and Pople J.A., Gaussian 98, Revision A6, Inc.: Pittsburg, PA, 1998

[49] DIPPR, Thermophysical Property Database, Thermophysical properties Laboratory, version 2005. [50] Nosé, S. "A unified formulation of the constant temperature molecular dynamics methods" J. Chem. Phys. 81 (1984), pp. 511-519. Hoover, W. G. "Canonical dynamics: Equilibrium phase-space distributions " Phys. Rev. A 31 (1985), pp. 1695-1697.

[51] Lagüe, P., Pastor, R. W. and Brooks, B. R. "Pressure-Based Long-Range Correction for LennardJones Interactions in Molecular Dynamics Simulations: Application to Alkanes and Interfaces" J. Phys. Chem. B 108 (2004), pp. 363-368.

[52] Thorpe, T.E., and Roger, J.W. Phil. Trans. Roy. Soc. (London) 71 (1987), A187

[53] Viswanath, D. S., and Natarajan, G. Data book on the viscosity of liquids, Hemisphere Publishing Corporation, USA, 1989.

[54] Pensado, A.S., Comuñas, M.J.P, Lugo, L., and Fernández, J. "Experimental Dynamic Viscosities of 2,3-Dimethylpentane up to $60 \mathrm{MPa}$ and from (303.15 to 353.15) K Using a Rolling-Ball Viscometer" , $J$. Chem. Eng. Data 50 (2005), pp. 849-855.

[55] Yaws, C. L. Chemical Properties Handbook: Physical, Thermodynamic, Environmental, Transport, Safety and Health Related properties for organic chemicals, McGraw-Hill Handbook, USA 1999.

[56] Chen H.W., and Tu, C.H., "Densities, Viscosities, and Refractive Indices for Binary and Ternary Mixtures of Acetone, Ethanol, and 2,2,4-Trimethylpentane", J. Chem. Eng. Data 50 (2005), pp. 12621269.

[57] Lagache, M.H., Ungerer, P., and Boutin, A. "Prediction of thermodynamic derivative properties of natural condensate gases at high pressure by Monte Carlo simulation", Fluid Phase Equilib. 220 (2004), pp 211-223.

[58] Montel, F., and Gouel, F., "A New Lumping Scheme of Analytical Data for Compositional Studies", SPE $n^{\circ} 13119$, 59th Annual Technical Conference and Exhibition, Houston, Texas, September 16-19, 1984

[59] Durand J.P., A. Fafet and A. Barreau, "Direct and Automatic Capillary GC Analysis for Molecular Weight Determination and Distribution in Crude Oils and Condensates up to C20", J. of High Res. Chromatography, 1989, p.203.

[60] Durand J.P., Bre, A., Beboulene, J.-J., Ducrozet, A., and Carbonneaux, S. "Improvement of Simulated Distillation Methods by Gas Chromatography in Routine Analysis", Oil \& Gas Science and Technology, Revue de l'IFP 54 (1999), pp. 431-438

[61] A breakdown of the composition is obtained by the evaporation of the fluid at different temperatures (colled True Boiling Point). The vapor obtained at each step is then analyzed separately.

[62] Nieto-Draghi, C., Bonnaud, P. and Ungerer, P. "Anisotropic United Atom model including the electrostatic interactions of methyl-benzenes. II. Transport Properties". J. Chem. Phys. C 111 (2007), pp 15942-15951.

[63] Norm NF M07-086. European committee for standardization, http://www.cen.eu

[64] API Alcohol and Ethers. A technical assessment of their applications as fuels and fuel components. API Publications 4621. $3^{\text {rd }}$ Edition, June 2001.

[66] Lohrenz, J., Bray, B.G., and Clark, C.R J. Pet. Tech. 16 (1964), pp. 1171-1176.

[67] Peng, D.Y., and Robinson, D.B., "A New Two-Constant Equation of State", Ind. Eng. Chem. Fundam. 15 (1976), 15, p. 59 
Table 1. Parameters of the AUA intermolecular potential used in this work. Molecular weight $(\mathrm{Mw})$ in $\mathrm{g} / \mathrm{mol},(\varepsilon)$ in $\mathrm{kJ} / \mathrm{mol},(\sigma)$ and $(\delta \mathrm{AUA})$ in $\AA$, bending constant $\left(\mathrm{k}_{\mathrm{b}}\right)$ in $\mathrm{kJ} / \mathrm{mol}$, bond distance $\left(\mathrm{d}_{\mathrm{ij}}\right)$ in $\AA$ and, charge in (e).

\begin{tabular}{|c|c|c|c|c|c|c|}
\hline & Group & Mw & $\varepsilon$ & $\sigma$ & $\delta \mathrm{AUA}$ & q \\
\hline Alcanes ([13],[14]) & $\mathrm{CH} 3$ & 15.03 & 120.15 & 3.607 & 0.216 & 0 \\
\hline \multirow[t]{7}{*}{ (linear and branched) } & $\mathrm{CH} 2$ & 14.03 & 86.29 & 3.431 & 0.384 & 0 \\
\hline & $\mathrm{CH}$ & 13.03 & 50.98 & 3.363 & 0.646 & 0 \\
\hline & $\mathrm{C}$ & 12.03 & 15.04 & 2.44 & 0 & 0 \\
\hline & bond dcc & 1.535 & & & & \\
\hline & Bending & linear & $\theta_{0}(\operatorname{deg})$ & 114 & & $\mathrm{~K}_{\mathrm{b}}=622.75058$ \\
\hline & & $\begin{array}{l}\text { branched } \\
\mathrm{C}-(\mathrm{CH})-\mathrm{C}\end{array}$ & $\theta_{0}(\operatorname{deg})$ & 112 & & $K_{b}=604.45688$ \\
\hline & & $\begin{array}{l}\text { branched } \\
\text { C-(C)-C }\end{array}$ & $\theta_{0}(\operatorname{deg})$ & 109 & & $\mathrm{~K}_{\mathrm{b}}=584.5656$ \\
\hline \multirow[t]{6}{*}{ Olefins [16] } & $\mathrm{CH} 2$ & 14.03 & 111.1 & 3.48 & 0.295 & 0 \\
\hline & $\mathrm{CH}$ & 13.03 & 90.6 & 3.32 & 0.414 & 0 \\
\hline & $\mathrm{C}$ & 12.03 & 61.9 & 3.02 & 0 & 0 \\
\hline & bond dec & 1.535 & & & & \\
\hline & bond $\mathrm{dc}=\mathrm{c}$ & 1.331 & & & & \\
\hline & Bending & $\begin{array}{l}\text { olefine } \\
\mathrm{C}=\mathrm{C}-\mathrm{C}\end{array}$ & $\theta_{0}(\operatorname{deg})$ & 119.7 & & $\begin{array}{c}\mathrm{K}_{\mathrm{b}}=1000.0 \\
\text { (rigid) }\end{array}$ \\
\hline \multirow[t]{8}{*}{ aromatics ([20],[21]) } & $\mathrm{CH} 3$ & 15.03 & 120.15 & 3.607 & 0.216 & 0 \\
\hline & $\mathrm{CH}$ & 13.03 & 75.6 & 3.361 & 0.315 & 0 \\
\hline & $\mathrm{C}$ & 12.03 & 35.43 & 3.361 & 0 & 0 \\
\hline & $+2 q$ & 0 & 0 & 0 & 0 & 8.13 \\
\hline & $-q$ & 0 & 0 & 0 & 0 & -4.065 \\
\hline & bond $\mathrm{dc}=\mathrm{c}$ & 1.4 & & & & \\
\hline & bond dcc & 1.535 & & & & \\
\hline & $\begin{array}{c}\text { negative } \\
\text { charge postion }\end{array}$ & $\begin{array}{c}\mathrm{z}=+0.4 \text { and } \\
\mathrm{z}=-0.4\end{array}$ & $\begin{array}{l}\text { positive } \\
\text { charge } \\
\text { postion }\end{array}$ & $\mathrm{y}=\mathrm{z}=0.0$ & & \\
\hline
\end{tabular}




\section{Page 33 of 57}

1 3
Table 2. Torsion parameters of the AUA intermolecular potential. Potential coefficients $\left(a_{i}\right)$ in $\mathrm{kJ} / \mathrm{mol}$.

\begin{tabular}{|c|c|c|c|}
\hline \multicolumn{2}{|c|}{ Single branched } & \multicolumn{2}{|c|}{ AUA4m (this work) } \\
\hline & AUA4 [14] & $\begin{array}{c}\mathrm{Ch}_{\mathrm{i}}-\mathrm{CH}-\mathrm{CH}_{2}-\mathrm{CH}_{\mathrm{i}} \\
(15 \%) \\
\end{array}$ & $\begin{array}{c}\mathrm{CH}_{\mathrm{i}}-\mathrm{CH}-\mathrm{CH}_{2}-\mathrm{CH}_{\mathrm{i}} \\
(40 \%) \\
\end{array}$ \\
\hline$a_{0}$ & 3.1015 & 3.7699 & 4.8865 \\
\hline$a_{1}$ & 7.6409 & 9.6459 & 12.9978 \\
\hline$a_{2}$ & 2.2294 & 2.2294 & 2.2294 \\
\hline$a_{3}$ & -14.4432 & -17.1165 & -21.5858 \\
\hline \multicolumn{2}{|c|}{ Double branched [47] } & \multicolumn{2}{|c|}{ AUA4m (this work) } \\
\hline$a_{i}$ & AUA4 & $\begin{array}{c}\mathrm{CH}_{\mathrm{i}}-\mathrm{C}-\mathrm{CH}_{2}-\mathrm{Ch}_{\mathrm{i}} \\
(15 \%) \\
\end{array}$ & $\begin{array}{c}\mathrm{CH}_{\mathrm{i}}-\mathrm{C}-\mathrm{CH}_{2}-\mathrm{Ch}_{\mathrm{i}} \\
(40 \%) \\
\end{array}$ \\
\hline$a_{0}$ & 1.9176 & 2.1874 & 2.6639 \\
\hline$a_{1}$ & 5.7526 & 6.5618 & 7.9912 \\
\hline$a_{2}$ & 0.0 & 0.0 & 0.0 \\
\hline$a_{3}$ & -7.6703 & -8.7493 & -10.6552 \\
\hline \multicolumn{2}{|c|}{$\begin{array}{l}\text { Double branched } \\
\text { (adjacent carbons) }\end{array}$} & \multicolumn{2}{|c|}{ AUA4m (this work) } \\
\hline$a_{i}$ & $\begin{array}{c}\mathrm{AUA}(4) \\
\text { (this work) }\end{array}$ & $\begin{array}{c}\mathrm{CH}_{\mathrm{i}}-\mathrm{CH}-\mathrm{CH}-\mathrm{Ch}_{\mathrm{i}} \\
(15 \%)\end{array}$ & $\begin{array}{c}\mathrm{CH}_{\mathrm{i}}-\mathrm{CH}-\mathrm{CH}-\mathrm{Ch}_{\mathrm{i}} \\
(40 \%) \\
\end{array}$ \\
\hline$a_{0}$ & -1.0708 & -0.5045 & 0.4801 \\
\hline$a_{1}$ & 3.6827 & 5.3821 & 8.3370 \\
\hline$a_{2}$ & 7.4678 & 7.4678 & 7.4678 \\
\hline \multirow[t]{8}{*}{$a_{3}$} & -10.3251 & -12.5911 & -16.5309 \\
\hline & ns [16] & AUA(4) & \\
\hline & $a_{i}$ & $\mathrm{CH}_{2}=\mathrm{CH}-\mathrm{CH}_{2}-\mathrm{CH}_{\mathrm{i}}$ & \\
\hline & $a_{0}$ & 2.2645 & \\
\hline & $a_{1}$ & -7.7995 & \\
\hline & $a_{2}$ & 1.8351 & \\
\hline & $a_{3}$ & 9.4369 & \\
\hline & $a_{4}$ & 0.0000 & \\
\hline
\end{tabular}


Table 3. Comparison of thermodynamic properties of 2,3-dimethyl butane computed with the torsion potentials developed for the branched alkans in adjacent carbons. Monte Carlo simulations in the Gibbs ensemble are compared with the experimental data of the DIPPR database (DIPPR, 2005) [49]. Liquid density $(\rho)$ in $\mathrm{kg} / \mathrm{m}^{3}$, saturation pressure $\left(\mathrm{P}^{\text {sat }}\right)$ in $\mathrm{kPa}$, enthalpy of vaporisation $\left(\Delta \mathrm{H}_{\mathrm{vap}}\right)$ in $\mathrm{kJ} / \mathrm{mol}$.

\begin{tabular}{cccc}
\hline & This work & Experimental data & $\begin{array}{c}\text { Deviation } \\
(\%)\end{array}$ \\
\hline$\rho$ & 515.6 & 519.3 & 0.7 \\
$\mathrm{P}^{\text {sat }}$ & 1024.2 & 925.6 & 10.6 \\
$\Delta \mathrm{H}_{\text {vap }}$ & 20.441 & 20.007 & 2.2 \\
\hline
\end{tabular}




\section{Page 35 of 57}

\section{8}

9

10

11

13

14

15

16

17

18

19

20

21

22

23

24

25

26

27

28

29

30

31

32

33

34

35

36

37

38

39

40

41

42

43

44

45

46

47

48

49

50

51

52

53

54

55

56

57

58

59

60

Table 4. Comparison of the simulation results of the AUA4 and AUA4m models for different C5-C7 branched molecules. The experimental data are taken form ref. ([52], [53], and [54]) and DIPPR database [49]. Temperature (T) in K, pressure (P) in bar, density $(\rho)$ in $\mathrm{kg} / \mathrm{m}^{3}$ and viscosity $(\eta)$ in $\mu$ Pa.s

\begin{tabular}{|c|c|c|c|c|c|c|c|c|c|c|c|}
\hline & & $\mathrm{T}$ & $\mathrm{P}$ & $\rho$ & $\Delta \rho$ & $\rho(\exp )$ & $\%$ Dev & $\eta(\mathrm{MD})$ & $\Delta \eta$ & $\eta(\exp )$ & $\%$ Dev \\
\hline \multirow[t]{3}{*}{ 2-methyl-butane } & AUA4 & 273.15 & 1 & 641.6 & 0.17 & & & 217.9 & 12.4 & 270.3 & -19.4 \\
\hline & AUA4m & & & 642.08 & 0.17 & & & 224.91 & 17.33 & & -16.8 \\
\hline & AUA4m & & & 616.69 & 0.18 & & -0.55 & 189.47 & 7.32 & & -10.6 \\
\hline \multirow[t]{5}{*}{ 2-methyl-pentane } & AUA4 & 273.15 & 1 & 680.78 & 0.13 & & & 243.7 & 17.6 & 372 & -34.5 \\
\hline & AUA4m & & & 681.1 & 0.16 & & & 270.94 & 19.65 & & -27.2 \\
\hline & AUA4m & & & 657.87 & 0.16 & & 0.71 & 228.08 & 15.81 & & -20.3 \\
\hline & AUA4 & 328.58 & 1 & 627.57 & 0.25 & & & 161.18 & 8.38 & 215.1 & -25.1 \\
\hline & AUA4m & & & 629.01 & 0.31 & & & 188.33 & 17.82 & & -12.4 \\
\hline \multirow[t]{2}{*}{ 3-methyl-pentane } & AUA4 & 273.15 & 1 & 681.26 & 0.27 & & & 271 & 18.2 & 395 & -31.4 \\
\hline & AUA4m & & & 682 & 0.09 & & & 289.55 & 17.89 & & -21.9 \\
\hline \multirow{3}{*}{$\begin{array}{l}\text { 2,2-dimethyl- } \\
\text { butane }\end{array}$} & AUA4m & & & 685.78 & 0.28 & & & 281.14 & 17.93 & & -41.1 \\
\hline & AUA4 & 298.15 & 1 & 661.95 & 0.24 & 661.6 & 0.05 & 205.24 & 19.05 & 351 & -41.5 \\
\hline & AUA4m & & & 661.23 & 0.25 & & -0.06 & 223.83 & 9.13 & & -36.2 \\
\hline \multirow[t]{4}{*}{ 3-ethyl-pentane } & AUA4 & 296.78 & 0.07 & 685.5 & 0.26 & 696.53 & -1.58 & 271.01 & 20.26 & 364 & -25.5 \\
\hline & AUA4m & & & 685.84 & 0.21 & & -1.53 & 293.83 & 13.09 & & -19.3 \\
\hline & AUA4 & 337.42 & 0.39 & 648.53 & 0.34 & 659.55 & -1.67 & 192.51 & 22.31 & 251.34 & -23.4 \\
\hline & AUA4m & & & 649.16 & 0.38 & & -1.58 & 230.69 & 28.82 & & -8.2 \\
\hline \multirow[t]{2}{*}{ 2-methyl-hexane } & AUA4 & 298.15 & 1 & 686.37 & 0.23 & 678.7 & 1.13 & 285.72 & 31.57 & 360.7 & -20.8 \\
\hline & AUA4m & & & 687.69 & 0.18 & & 1.32 & 304.70 & 22.03 & & -15.5 \\
\hline 3-methyl-hexane & AUA4 & 294.28 & 0.067 & 691.98 & 0.25 & 687.41 & 0.66 & 301.64 & 50.45 & 373.58 & -19.3 \\
\hline \multirow{10}{*}{$\begin{array}{l}\text { 2,3-dimethyl- } \\
\text { pentane }\end{array}$} & AUA4 & & 300 & 705.58 & 0.09 & 711.6 & -0.85 & 360.85 & 18.72 & 485 & -25.6 \\
\hline & AUA4m & & & 706.59 & 0.15 & & -0.70 & 389.09 & 24.63 & & -19.8 \\
\hline & AUA4 & & 600 & 725.53 & 0.11 & 730.3 & -0.65 & 483.29 & 22.68 & 624 & -22.5 \\
\hline & AUA4m & & & 726.31 & 0.12 & & -0.55 & 513.00 & 34.52 & & -17.8 \\
\hline & AUA4 & 333.15 & 1 & 652.4 & 0.32 & 659.7 & -1.11 & 226 & 17.87 & 262 & -13.7 \\
\hline & AUA4m & & & 653.53 & 0.19 & & -0.94 & 224 & 16.78 & & -14.5 \\
\hline & AUA4 & & 300 & 684.45 & 0.19 & 690.5 & -0.88 & 314.94 & 24.45 & 369 & -14.7 \\
\hline & AUA4m & & & 685.25 & 0.15 & & -0.76 & 325.06 & 35.25 & & -11.9 \\
\hline & AUA4 & & 600 & 706.82 & 0.19 & 719.9 & -1.82 & 368.58 & 23.03 & 474 & -22.2 \\
\hline & AUA4m & & & 707.58 & 0.16 & & -1.71 & 405.27 & 32.9 & & -14.5 \\
\hline \multirow[t]{2}{*}{ AAD } & AUA4 & & & & & & 0.92 & & & & 24.4 \\
\hline & AUA4m & & & & & & 0.88 & & & & 18.9 \\
\hline
\end{tabular}


Table 5. Comparison of the simulation results of the AUA4 and AUA4m models for different C8-C10 branched molecules. The experimental data are taken form ref. ([55], and [56]) and the DIPPR database [49]. Temperature (T) in K, pressure (P) in bar, density $(\rho)$ in $\mathrm{kg} / \mathrm{m}^{3}$ and viscosity $(\eta)$ in $\mu$ Pa.s

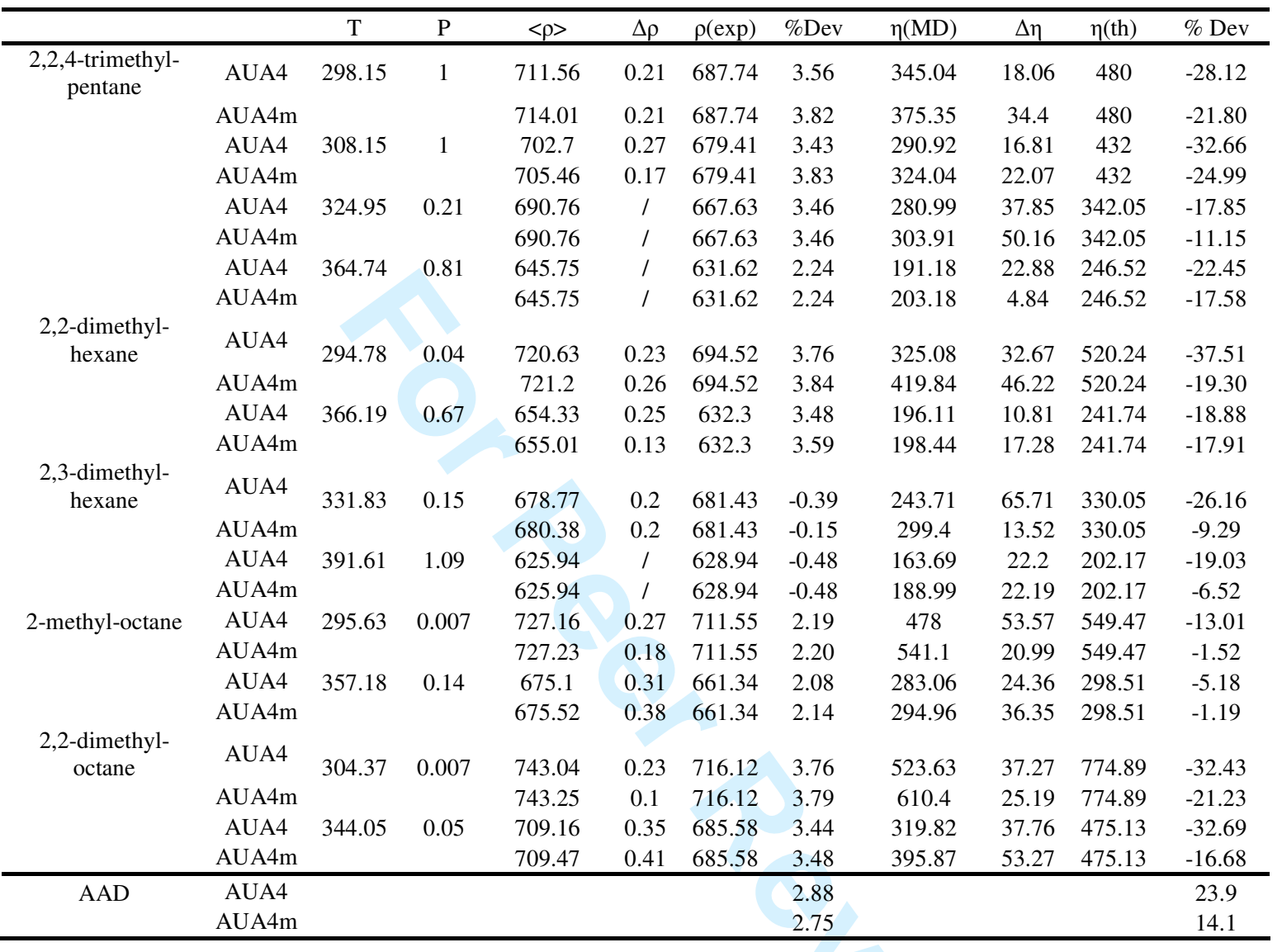




\section{Page 37 of 57}

1
Table 6. Comparison of the simulation results of the AUA4 model for olefin molecules chAUA4 model of 1,2,4-trimethyl benzene. The experimental data are taken form ref. [55] and the DIPPR database [49]. Temperature (T) in K, pressure $(P)$ in bar, density $(\rho)$ in $\mathrm{kg} / \mathrm{m}^{3}$ and viscosity $(\eta)$ in $\mu$ Pa.s

\begin{tabular}{|c|c|c|c|c|c|c|c|c|c|c|}
\hline & $\mathrm{T}$ & $\mathrm{P}$ & $\langle\rho\rangle$ & $\Delta \rho$ & $\rho(\exp )$ & $\%$ Dev & $\eta(M D)$ & $\Delta \eta$ & $\eta(\exp )$ & $\%$ Dev \\
\hline \multirow[t]{2}{*}{ 1-butene } & 203.15 & 0.0304 & 690.3 & 0.21 & 694.13 & -0.55 & 330.1 & 16 & 378 & -12.67 \\
\hline & 238.15 & 0.27 & 652.3 & 0.21 & 657.7 & -0.82 & 209.0 & 18 & 250 & -16.40 \\
\hline \multirow[t]{2}{*}{ trans-2-butene } & 298.15 & 1 & 599.8 & 0.18 & 599.3 & 0.08 & 145.7 & 10 & 183 & -20.3 \\
\hline & 400 & 1 & 433.4 & 0.14 & 432.7 & 0.16 & 56.9 & 5 & 62 & -14.0 \\
\hline \multirow[t]{3}{*}{ 1-hexene } & 290 & 0.1675 & 680 & 0.18 & -- & -- & 240.0 & 12 & 257 & -6.61 \\
\hline & 333 & 0.899 & 640 & 0.17 & 634.9 & 0.80 & 171.0 & 15 & 199 & -14.07 \\
\hline & 400 & 5.45 & 560 & 0.13 & 558.6 & 0.25 & 115.1 & 11 & 144 & -20.07 \\
\hline \multirow[t]{2}{*}{ trans-2-hexene } & 298.15 & 1 & 680.3 & 0.2 & 673.2 & 1.05 & 277.0 & 20 & 281 & -1.42 \\
\hline & 400 & 1 & 572.7 & 0.18 & 566.1 & 1.16 & 108.6 & 18 & 125 & -13.52 \\
\hline AAD & & & & & & 0.61 & & & & 11.9 \\
\hline \multirow[t]{2}{*}{$\begin{array}{c}1,2,4 \text {-thrimethyl } \\
\text { benzene }\end{array}$} & 298.15 & 1 & 879.5 & 0.2 & 872.18 & 0.84 & 858 & 30.0 & 835 & 2.75 \\
\hline & 400 & 1 & 790.8 & 0.4 & 786.6 & 0.53 & 287 & 15.0 & 293 & -2.05 \\
\hline AAD & & & & & & 0.69 & & & & 2.40 \\
\hline
\end{tabular}

Deleted: 49

Deleted: 46 
Table 7. Gasoline composition distributed by main families of hydrocarbons and by the population of carbon number as obtained from the Carburane ${ }^{\circledR}$ gas chromatography ([59], [60]). Compositions are expressed in weight $(\mathrm{Xw})$, mole $(\mathrm{Xm})$ and volume $(\mathrm{Xv})$ fraction.

\begin{tabular}{cccc}
\hline By Family & $\mathrm{Xw}(\%)$ & $\mathrm{Xm}(\%)$ & $\mathrm{X}_{\mathrm{v}}(\%)$ \\
\hline Paraffins & 8.394 & 10.673 & 9.938 \\
Iso-paraffins & 31.361 & 29.979 & 34.464 \\
Naphtenes & 4.654 & 4.519 & 4.509 \\
Aromatics $^{\text {Olefins }}$ & 40.292 & 36.241 & 34.373 \\
Oxygenated $^{\mathrm{a}}$ & 12.648 & 15.781 & 14.055 \\
\hline By No of C $^{2.651}$ & 2.807 & 2.661 \\
\hline C3 & 0.055 & 0.116 & 0.080 \\
C4 & 5.793 & 9.405 & 7.320 \\
C5 & 18.414 & 23.463 & 20.911 \\
C6 & 10.588 & 11.848 & 10.985 \\
C7 & 18.958 & 18.715 & 17.608 \\
C8 & 26.887 & 22.838 & 25.614 \\
C9 & 10.526 & 8.029 & 9.494 \\
C10 & 4.460 & 3.063 & 3.914 \\
C11 & 2.341 & 1.442 & 2.130 \\
C12 & 1.834 & 1.008 & 1.806 \\
C13 & 0.121 & 0.062 & 0.114 \\
C14 & 0.014 & 0.006 & 0.013 \\
C15 & 0.011 & 0.005 & 0.01 \\
\hline
\end{tabular}




\section{Page 39 of 57}

1

3

4

5

6

7

8

9

10

11

12

13

14

15

16

17

18

19

20

21

22

23

24

25

26

27

28

29

30

31

32

33

34

35

36

37

38

39

40

41

42

43

44

45

Table 8. Gasoline composition as obtained by the lumping methodology for 12 pseudo constituents. Composition in mole fraction, critical temperature (Tc) in $\mathrm{K}$, critical pressure

(Pc) in bar, critical volume $(\mathrm{Vc})$ in $\mathrm{m}^{3} / \mathrm{kmol}$, molecular weight $(\mathrm{Mw})$ in $\mathrm{kg} / \mathrm{mol}$. Shear viscosity $(\eta)$ in $\mu$ Pa.s.

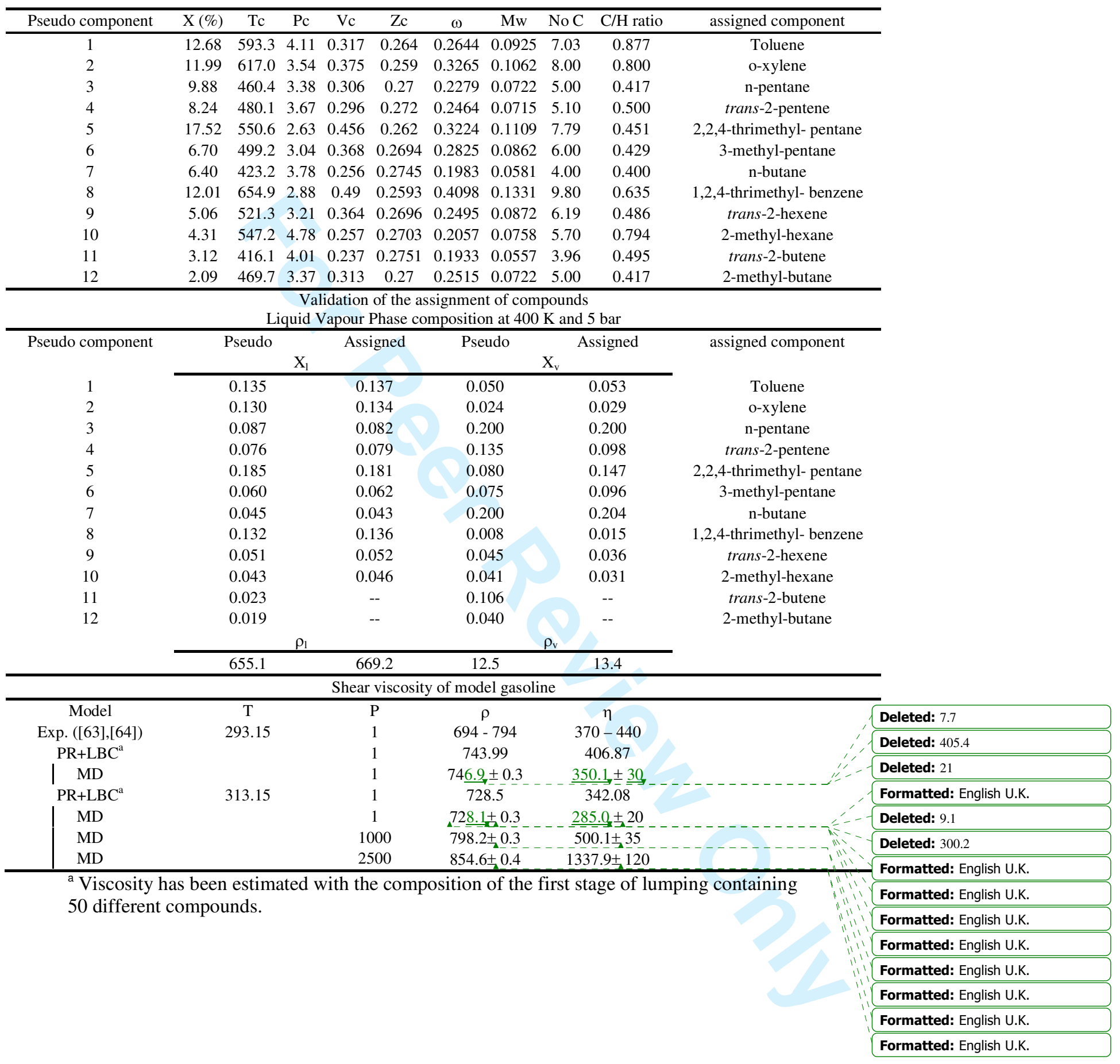


Figure 1.Different branched molecules used in the optimisation process: 2-methyl pentane (a) structure and (b) Newman representation. 2,2-dimethyl butane (c) structure and (d) Newman representation. 2,3-dimethyl pentane (e) structure and (f) Newman representation.

Figure 2. Global (a) and individual (b) torsion potential around the $\mathrm{CH}_{3}-\mathrm{CH}-\mathrm{CH}_{2}-\mathrm{CH}_{2}$. Dihedral angle distribution for 2-methyl pentane at $273 \mathrm{~K}$ and 1 bar. Comparison between AUA4 and the new AUA4m model.

Figure 3. Global (a) and individual (b) torsion potential around the $\mathrm{CH}_{3}-\mathrm{CH}-\mathrm{CH}_{2}-\mathrm{CH}_{3}$. Dihedral angle distribution for 2,2-dimethyl butane at $273 \mathrm{~K}$ and 1 bar. Comparison between AUA4 and the new AUA4m model.

Figure 4. Global (a) and individual (b) torsion potential around the $\mathrm{CH}_{3}-\mathrm{CH}-\mathrm{CH}-\mathrm{CH}_{2}$. Dihedral angle distribution for 2,3-dimethyl pentane at $303 \mathrm{~K}$ and 1 bar. Comparison between AUA4 and the new AUA4m model.

Figure 5. Comparison of the torsion correlation function for the different types of torsion optimised, and reorientational relaxation time $\tau_{\mathrm{ci}}$ of the $\mathrm{CH}$ vectors of carbon atoms involved in the different torsion types. (a) and (b) for 2-methyl pentane at $273 \mathrm{~K}$ and 1bar; (b) and (c) for 2,2-dimethyl butane at $273 \mathrm{~K}$ and 1 bar, and (c) and (f) for 2,3-dimethyl pentane at $303 \mathrm{~K}$ and 1 bar. Numbers before each $\mathrm{CHi}$ group correspond to the atoms described in figure 1 for each type of molecule. Comparison between AUA4 and the new AUA4m model.

Figure 6. Variation of the shear viscosity for branched alkanes in function of the number and position of the methyl groups. (a) C6 molecules at $273 \mathrm{~K}$ and 1 bar, and (b) C7-C8 molecules at $294 \mathrm{~K}$ and 1 bar. Variation of the shear viscosity of different "2-methyl-" branched alkanes in function of the size of the chain at $298 \mathrm{~K}$ and 1 bar. Comparison between AUA4 and the new AUA4m model. Experimental data form refs. ([52],[53],[54])

Figure 7. Comparison absolute average deviation between the simulation results and the experimental data for the different molecules involving the three different types of torsion, A: single branced; B, double branched and $\mathrm{C}$, double branched in adjacent carbon atoms. Comparison between AUA4 and the new AUA4m model.

| Figure 8. Lumping method with "dynamical cluster" 
a)

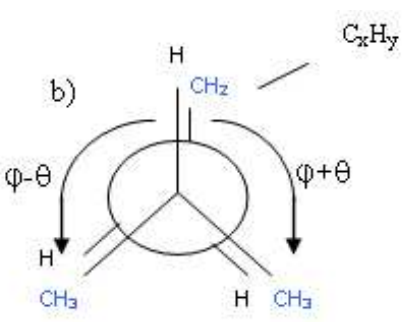

c)

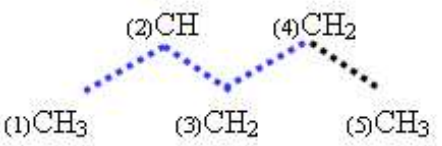

(I) $\mathrm{CH}_{3} \quad$ (3) $\mathrm{CH}_{2} \quad$ (S) $\mathrm{CH}_{3}$<smiles>[CH2]C[CH2]</smiles>

(1) $\mathrm{CH}_{3} \quad$ (3) $\mathrm{CH}_{2}$

e)

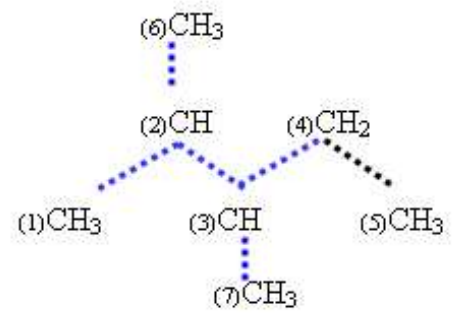

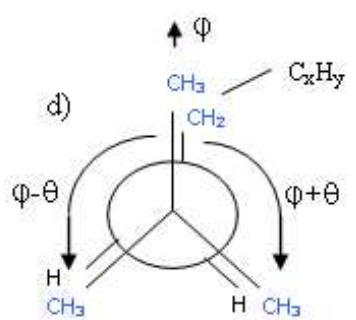

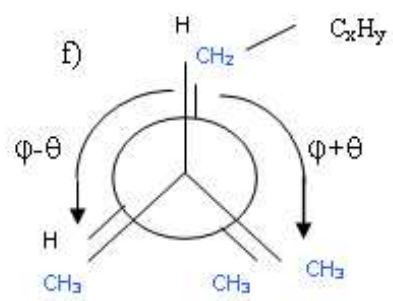

Differnt branched molecules used in the optimisation process: 2-methyl pentane (a) structure and (b) Newman representation. 2,2-dimethyl butane (c) structure and (d) Newman representation. 2,3-dimethyl pentane (e) structure and (f) Newman representation $169 \times 143 \mathrm{~mm}$ (96 x 96 DPI) 
4

5 5 5

5
5
5
5
5

5

5
6

$30-$ - AUA4m $(+40 \%)$ -- AUA4m $(+15 \%)$ - AUA4 a)

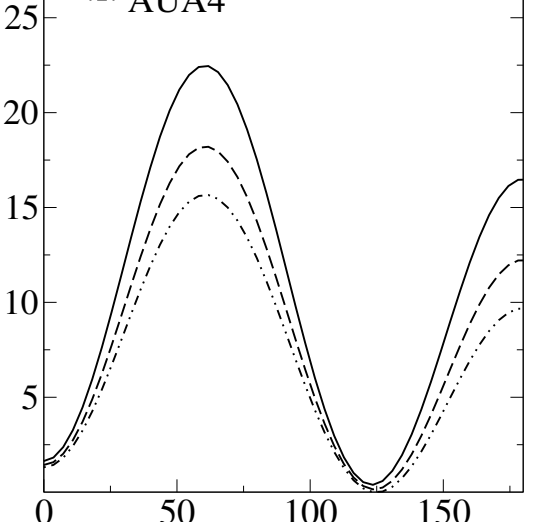 )

20

Dihedral angle (degrees) 


\section{Page 43 of 57}

1

2

3

4

5

6

10

11

12

13

14

15

16

17

18

19

20

21

22

24

25

26

27

28

29

30

34

35

36

37

38

39

40

41

42

43

44

45

46

4

4
4

4

5
5
5
5
5
5
5
5
5
5

- AUA4m (+40\%)

-- AUA4m (+15\%)

b)

- AUA4

15

AUA4

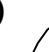

5
6

59
60

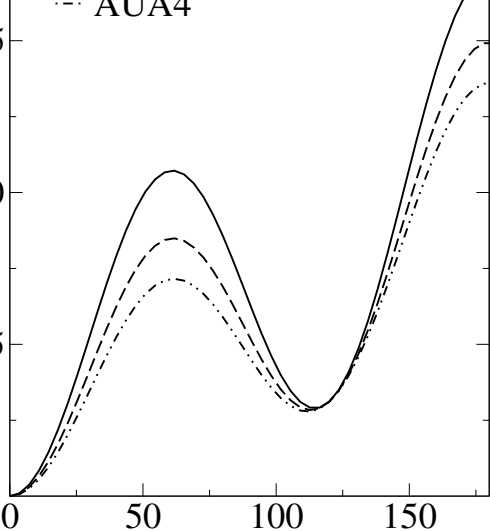

Dihedral angle (degrees)

http://mc.manuscriptcentral.com/tandf/jenmol 
39

40

41

42

43

44

45

46

47

4

4

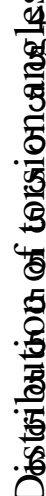

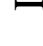

7

$9_{0.03-}-$ AUA4m $\left.(+15 \%) \quad c\right)$
- AUA4

)
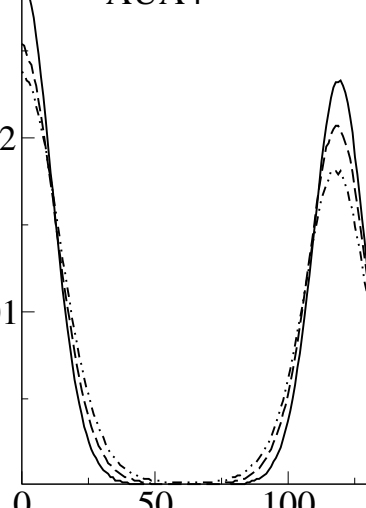

Dihedral angle $100 \quad 150$ 


\section{Page 45 of 57}

1

2

3

4

5

6

10

11

12

13

14

15

16

17

18

19

20

21

22

23

24

25

26

27

28

29

30

34

35

36

37

38

39

40

41

42

43

44

45

46

4

4

4
5

5
5
5
5
5
5
5
5

5
5
5
5
5
5
5

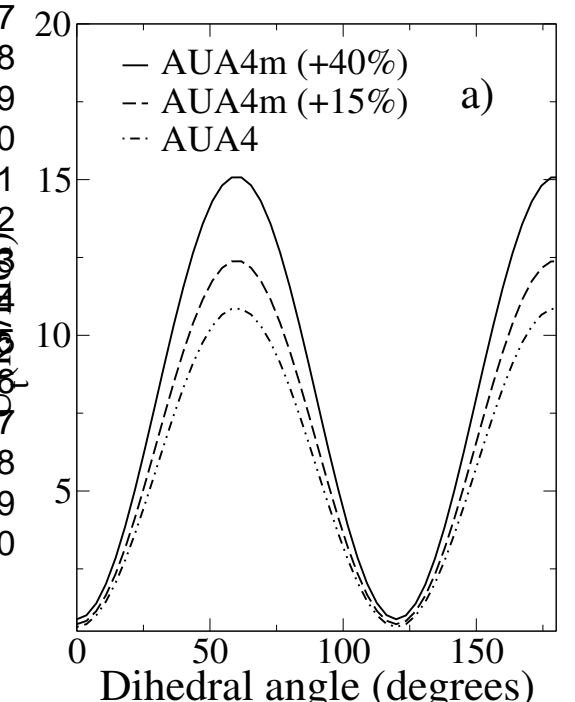

http://mc.manuscriptcentral.com/tandf/jenmol 


5

5

5

5
5

5

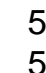

55 56

58

5

60

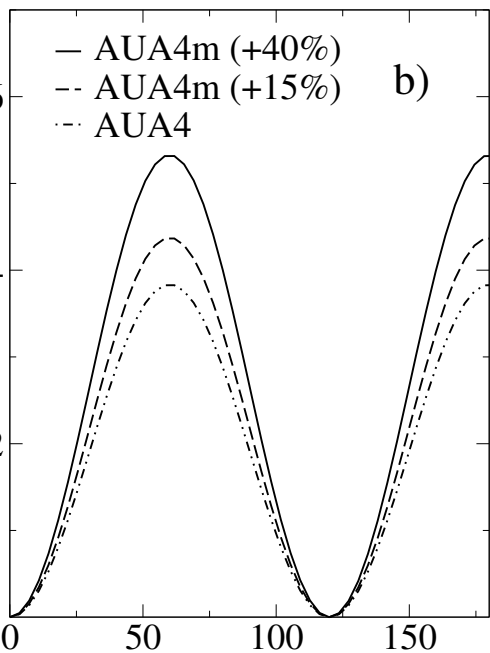

http://mc.manuscriptcentral.com/tandf/jenmol 


\section{Page 47 of 57}

1

2

3

4

5

6

7

10

11

12

13

14

15

16

17

18

19

20

21

22

23

24

25

26

27

28

29

30

31

32

33

34

35

36

37

38

39

40

41

42

43

44

45

46

47

c)

4

魚

离

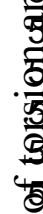

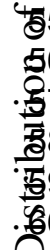

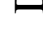

- AUA4m $(+40 \%)$

-- AUA4m $(+15 \%)$

- AUA4
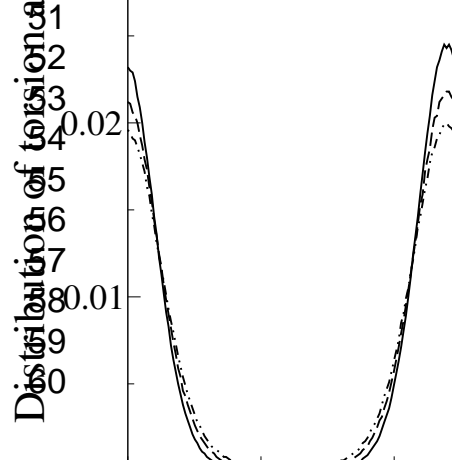
39

40

41

42

43

44

45

46

4

4
4

4
5

5
5
5
5
5
5
5
5
5

5
5
5
5
5
5
5
6

- AUA4m (+40\%)

-- AUA4m (+15\%)

a)

0 40- AUA4

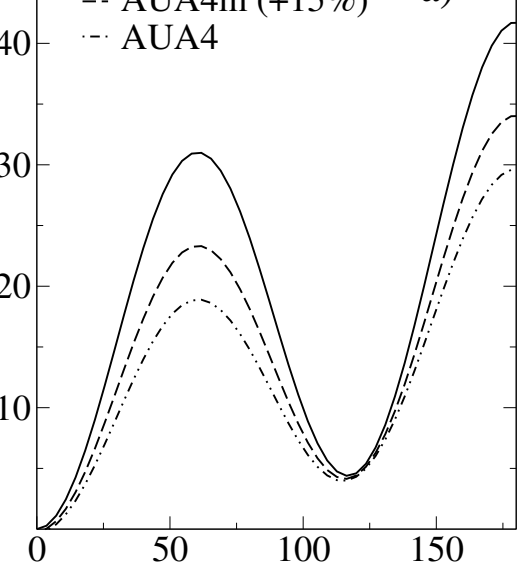

http://mc.manuscriptcentral.com/tandf/jenmol 


\section{Page 49 of 57}

1

2

3

4

5

6

10

11

12

13

14

15

16

17

18

19

20

21

22

24

25

26

27

28

29

30

31

32

33

34

35

36

37

38

39

40

41

42

43

44

45

46

4

4

4
5

5
5
5
5
5
5
5
5

5
5
5
5
5
5
5

5

60

$20-$ AUA4m (+40\%)

-- AUA4m $(+15 \%)$

b)

- AUA4

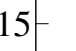

10

60 


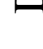

- AUA4m $(+40 \%)$

4 -- AUA4m $(+15 \%) \quad$ c) -. AUA4

http://mc.manuscriptcentral.com/tandf/jenmol 
32

33

34

35

3
3
3
3
3 4

4
4
4
9
4
15
5
5
5
5

4
4
4
8
4
5
5
5
5
5
5

5

36

37

$\begin{array}{ll}37 & 1.4 \\ 39 & 1.3\end{array}$

1

431

(2) $\mathrm{CH} \quad(3) \mathrm{CH}_{2}(4) \mathrm{CH}_{2}$

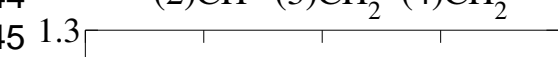

d)

76 1.2 $\triangle$ AUA4m $(+40 \%)$



अ

6

e)

http://mc.manuscriptcentral.com/tandf/jenmol 


\section{Page 53 of 57}

1

2

3

4

5

6

7

8

9

10

11

12

13

14

15

16

17

18

19

20

21

22

23

24

25

26

27

28

29

34

35

36

37

38

39

40

41

42

43

44

45

46

4

4

4

5

5

5

5
5
5
5
5
5
5

5
5
6

6

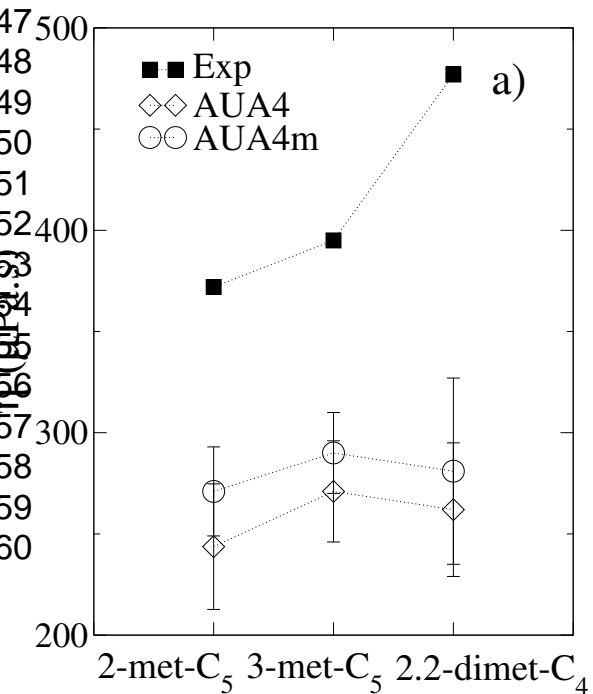

http://mc.manuscriptcentral.com/tandf/jenmol 
1

2

3

4

5

6

7

8

9

10

11

12

13

14

15

16

17

18

19

20

21

22

23

24

25

26

27

28

29

30

31

32

33

34

35

36

37

38

39

40

41

42

43

44

45

46

4

4

4
5
5

5
5
5

5

5
5
5
5

- Exp

$\diamond \diamond$ AUA4

b)

59

60300
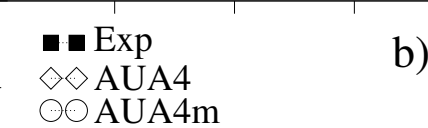
.

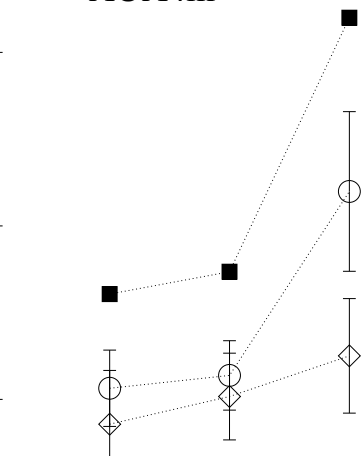




\section{Page 55 of 57}

1

2

3

4

5

6

7

8

10

11

12

13

14

15

16

17

18

19

20

21

22

23

24

25

26

27

28

29

34

35

36

37

38

39

40

41

42

43

44

45

46

4

4

4

4

5

5

5

5
5
5
5
5
5

$48600 \square$ —Exp

$49-\diamond \diamond$ AUA4

500- $\bigcirc$ AUA4m

52

58

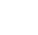

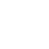

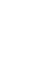

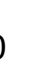

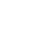

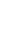

(1)

(2)

(n)

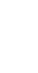

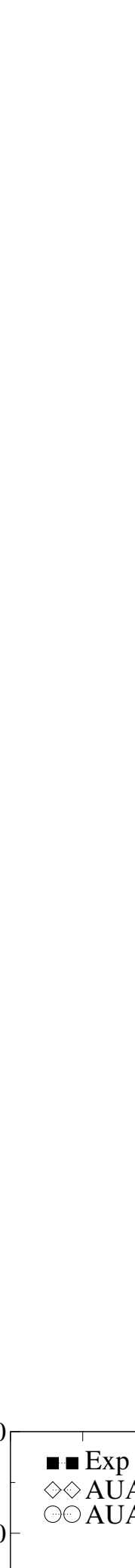


2

4

49
50
51
52

5

5
5
5
5
5
5




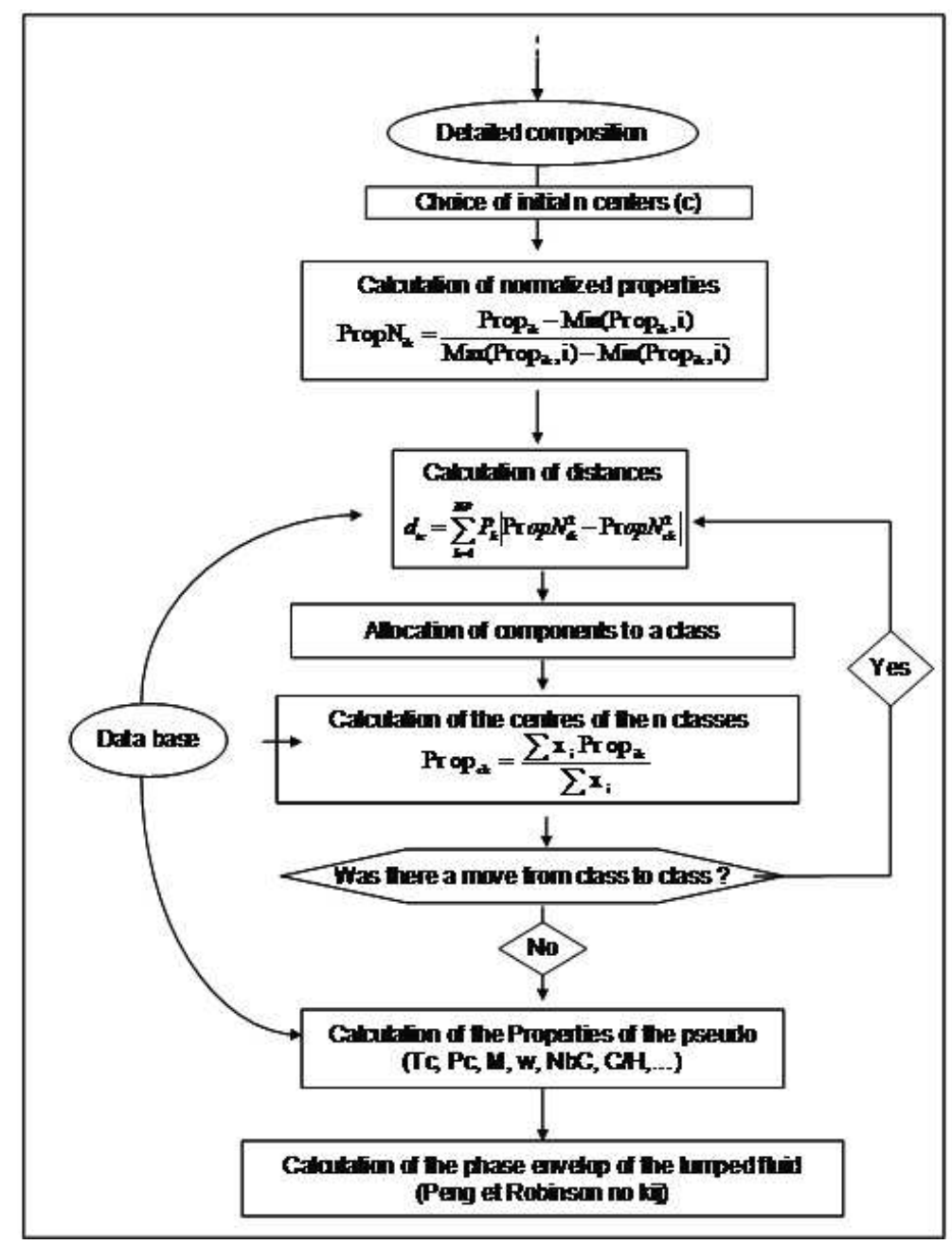

Lumping method "nuées dynamiques" $169 \times 168 \mathrm{~mm}$ ( $96 \times 96$ DPI) 